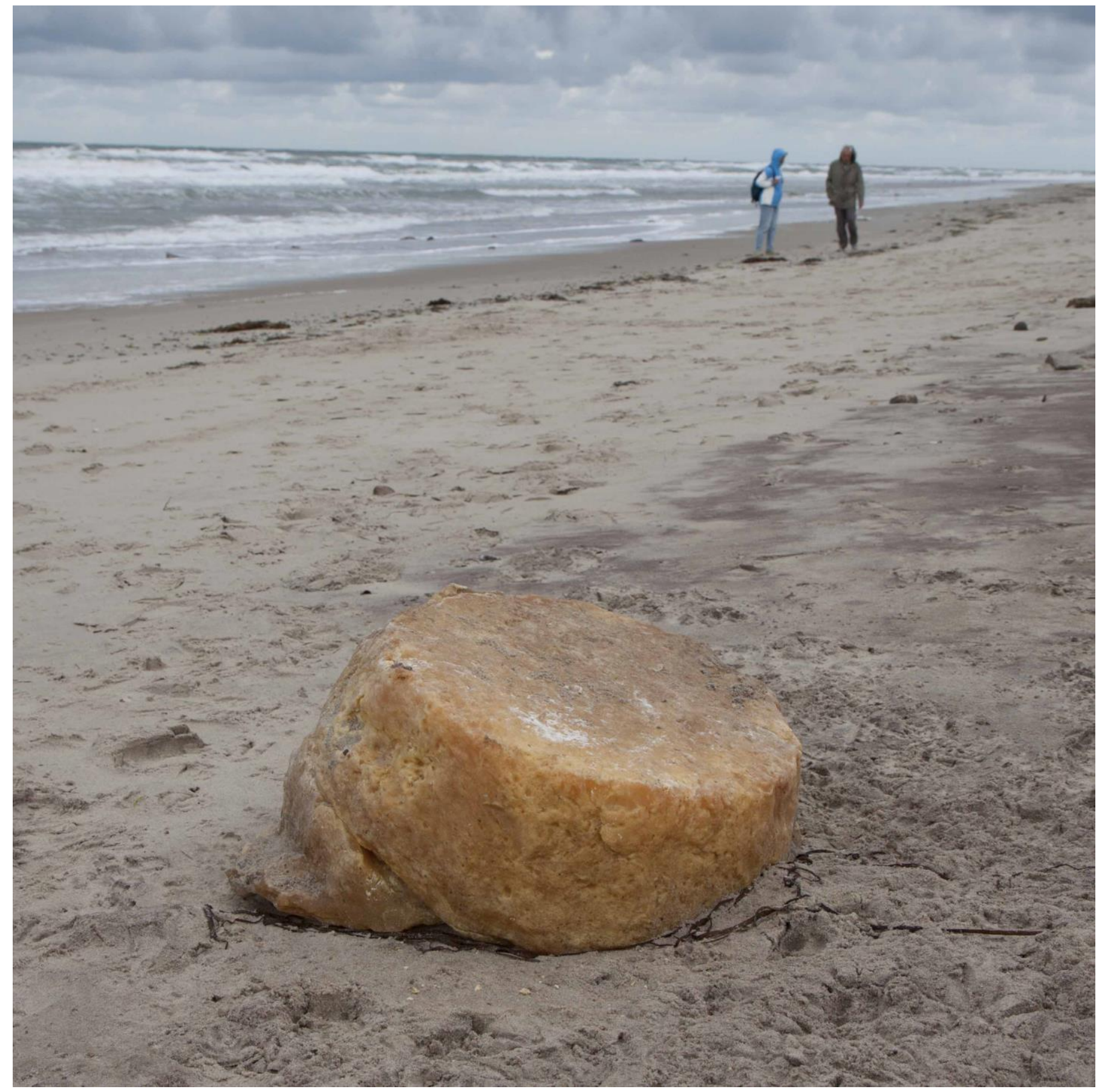

\title{
Monitoring van paraffine-achtige stoffen op Nederlandse stranden en in magen van Noordse Stormvogels
}





\section{Monitoring van paraffine-achtige stoffen op Nederlandse stranden en in magen van Noordse Stormvogels}

Auteur(s): $\quad$ Jan Andries van Franeker, Susanne Kühn, Michiel Kotterman \& Christiaan Kwadijk

Wageningen Marine Research, Ankerpark 27, 1781 AG Den Helder

Wageningen Marine Research, Haringkade 1, 1976 CP IJmuiden

Dit onderzoek is uitgevoerd in het kader van het KB-Programma System Earth Management 2018: KB-24-002036 (WMR projectnummer 43183000 57).

Wageningen Marine Research

Den Helder, Maart 2019

VERTROUWELIJK Nee

Wageningen Marine Research rapport C001/19 
Keywords:

paraffine, palmolie; strand; zwerfvuil; Noordse Stormvogel; Fulmarus glacialis; monitoring; OSPAR; KRM

Opdrachtgever: Kennisbasis programma System Earth Management 2018

BAS code KB-24-002-036

Dit rapport is gratis te downloaden van https://doi.org/10.18174/467759

Wageningen Marine Research verstrekt geen gedrukte exemplaren van rapporten.

Wageningen Marine Research is ISO 9001:2015 gecertificeerd.

Foto omslag:

Groot blok paraffine- of palmvetachtig materiaal op het strand van Texel (Foto: J.A. van Franeker)

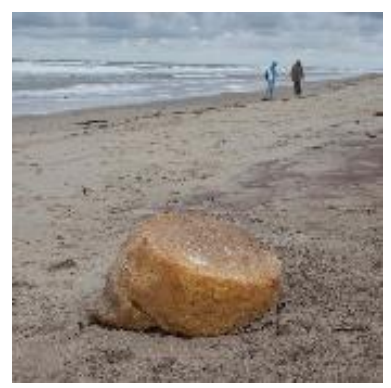

(C) Wageningen Marine Research

Wageningen Marine Research, instituut binnen de rechtspersoon Stichting Wageningen Research, hierbij vertegenwoordigt door Dr. M.C.Th. Scholten, Algemeen directeur

KvK nr. 09098104,

WMR BTW nr. NL 8113.83.696.B16.

Code BIC/SWIFT address: RABONL2U

IBAN code: NL 73 RABO 0373599285
Wageningen Marine Research aanvaardt geen aansprakelijkheid voor gevolgschade, noch voor schade welke voortvloeit uit toepassingen van de resultaten van werkzaamheden of andere gegevens verkregen van Wageningen Marine Research opdrachtgever vrijwaart Wageningen Marine Research van aanspraken van derden in verband met deze toepassing.

Alle rechten voorbehouden. Niets uit deze uitgave mag weergegeven en/of gepubliceerd worden, gefotokopieerd of op enige andere manier gebruikt worden zonder schriftelijke toestemming van de uitgever of auteur. 


\section{Inhoud}

$1 \quad$ Samenvatting $\quad 5$

2 Abstract $\quad 6$

$\begin{array}{lll}3 & \text { Inleiding } & 7\end{array}$

4 Materiaal en Methoden $\quad 9$

$\begin{array}{llr}4.1 & \text { Strandonderzoek } & 9\end{array}$

$\begin{array}{ll}4.2 & \text { Stormvogelonderzoek } \\ 4.3 & \text { Chemische analyses }\end{array}$

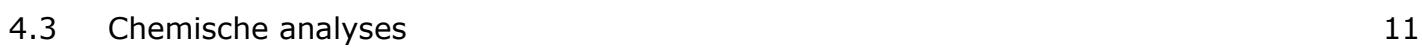

4.4 Analyse van gegevens $\quad 11$

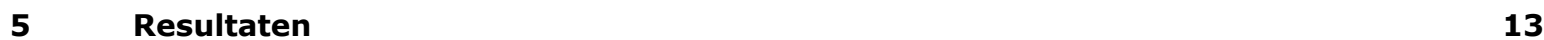

5.1 Identificatie van op strand gevonden paraffine- of palmvet achtige substanties. 13

5.2 Frequentie van voorkomen en hoeveelheid paraffine- of palmvet achtige substanties in de magen van in Nederland gevonden Noordse Stormvogels

5.3 Identificatie van paraffine-of palmvet achtige substanties in de magen van in Nederland gevonden Noordse Stormvogels $\quad 19$

6 Discussie $\quad 23$

$\begin{array}{llr}7 & \text { References } & 25\end{array}$

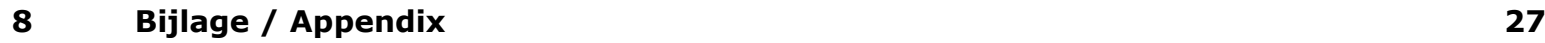

$\begin{array}{llr}9 & \text { Kwaliteitsborging } & 30\end{array}$

$\begin{array}{llr}10 & \text { Verantwoording } & 31\end{array}$ 


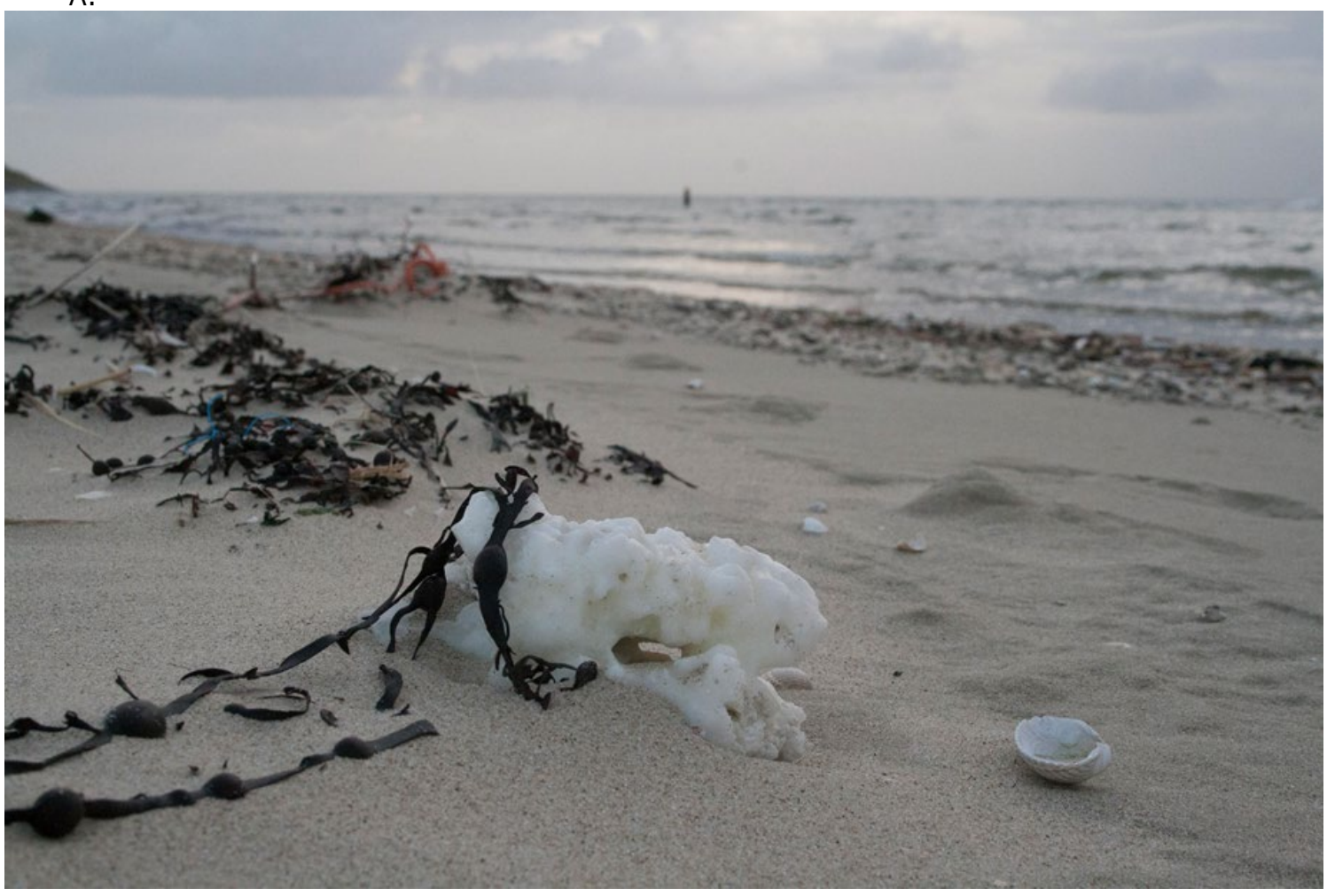

B.

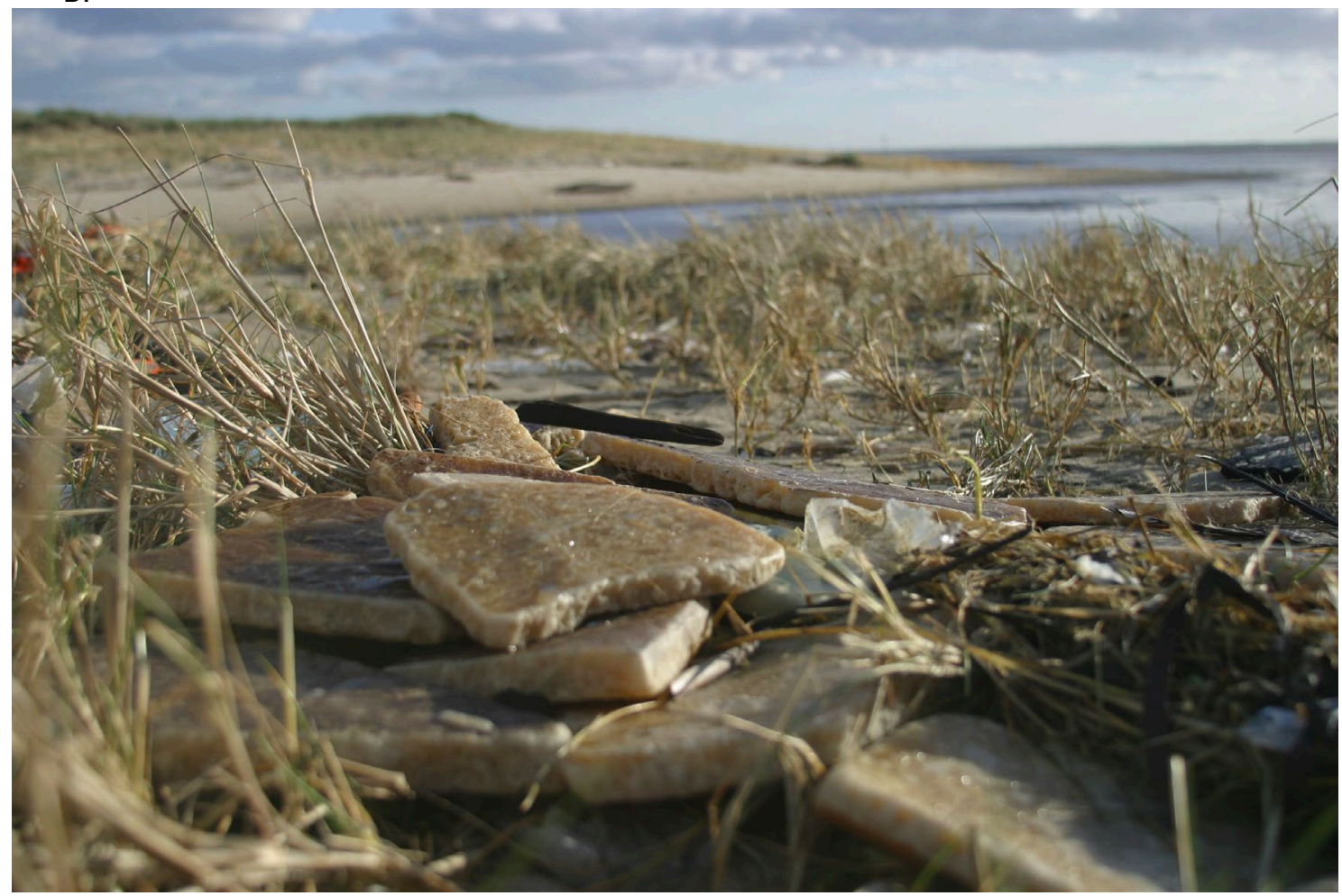

Figuur 1 Algemene vormen van paraffine- of palmvet-achtige substanties op het strand van Texel. De bovenste vorm (A.) is vermoedelijk vloeibaar (verhit) in zee gekomen en daarin in grillige vormen snel gestold. De onderste vorm (B.) is als stevige korst, ontstaan door korstvorming op, of sedimentvorming onder de in principe vloeibaar vervoerde lading.

Figure 1 Common types of paraffin-or palmfat-like substances on the beaches of the island of Texel. The upper form (A.) was probably discharged in a heated fluid state and solidified in irregular shapes in cold seawater. The lower type is a solid crust, with a likely source as either a surface crust or sediment layer in cargo transported as fluids. 


\section{$1 \quad$ Samenvatting}

In het kader van het KB-Programma System Earth Management 2018 (KB-24-002-036) werd een verkennend onderzoek uitgevoerd van de mogelijkheden tot monitoring van paraffine- of palmvetachtige substanties op Nederlandse stranden en in de magen van dood gevonden Noordse Stormvogels. Zulke stoffen worden deels legaal geloosd door tankschepen die op zee hun ruimen schoonmaken.

Paraffine werd chemisch geïdentificeerd op basis van de aanwezigheid van alkanen. In detail moet nog worden uitgezocht welke andere aardolie derivaten vergelijkbare pieken vertonen. Bij afwezigheid van alkanen werd door verdere analyse getracht de aard van het onderzochte materiaal te bepalen.

Het op stranden verzamelde materiaal bleek in 30 van de 32 gevallen (94\%) te bestaan uit paraffine. Eén monster bestond uit palmvet, één monster was onduidelijk doch bevatte ftalaten (bijv. gebruikt als weekmakers in plastics). Het uit vogelmagen verzameld materiaal verschilde sterk. In slechts $31 \%$ van de 32 onderzochte monsters werd paraffine aangetroffen. In $41 \%$ zaten plantaardige vetten, vooral gerelateerd aan palmolie. Het restant van de monsters toonde veelal een onduidelijke mix van plantaardige en dierlijke vetten. Het verschil tussen strand en vogelmagen heeft meerdere mogelijke achtergronden, waaronder aantrekkelijkheid voor dieren, smeltpunt en biologische afbreekbaarheid. Ruim 20\% van de in Nederland gevonden Noordse Stormvogels heeft paraffine- of palmvet-achtige stoffen in de maag. Over gezondheidsschade voor de dieren is nog niet veel duidelijk. Door de jaren heen zijn geen duidelijke veranderingen waarneembaar, de hoeveelheid ingeslikt materiaal verschilt enorm. In recente jaren lijkt de frequentie van voorkomen iets af te nemen, maar er is geen sprake van een statistisch betrouwbare trend. Het zou zinvol zijn om de registratie van chemisch verdachte materialen in stormvogelmagen toe te voegen aan het bestaande monitoringsprogramma van plastics voor OSPAR en de EU KaderRichtlijn Marien. Uiteraard is chemische analyse van het op stranden en in vogelmagen aangetroffen materiaal daarbij aan te bevelen. 


\section{Abstract}

Within the KB-Program System Earth Management 2018 (KB-24-002-036) a pilot study was conducted into options to monitor of paraffin- or palmfat-like substances on Dutch beaches and in stomachs of corpses of beached Northern Fulmars. Such substances are, in part legally, discharged by tanker ships cleaning their tanks at sea.

Paraffin was chemically identified by the presence of alkanes in the samples. It remains to be investigated in detail which other mineral oil derivatives may show similar alkane patterns. In the absence of alkanes further analyses were conducted to assess the type of material involved.

Samples taken from beaches showed to be paraffin in 30 of 32 analyses (94\%). One sample contained palmoil related substances, one sample remained unclear but contained phthalates (eg used as plastic softeners). The materials from bird stomachs proved to be different. Paraffin was only found in $31 \%$ of 32 samples. In $41 \%$ of the stomachs vegetable fatty substances were demonstrated, usually palm oil related. The remainder of samples had an uncertain mix of vegetable and animal fats. The difference between beaches and bird stomachs may have several backgrounds, including attraction for wildlife, melting points, and biodegradability.

Over $20 \%$ of fulmars found in the Netherlands has chemical suspect materials in the stomach. Not much is known about potential health impacts. Over the years no clear changes can be detected. Quantities of material ingested are highly variable. Frequency of occurrence may slightly reduce over the more recent years, but there is no statistically significant trend. It would make sense to add records on chemical suspect materials in fulmar stomachs to the existing monitoring of plastics in the framework of OSPAR and the EU Marine Strategy Framework Directive. Clearly chemical analyses of substances encountered on beaches and in birds is additionally recommended. 


\section{$3 \quad$ Inleiding}

In de afgelopen jaren verschenen in de media geregeld berichten over vervuiling van stranden met paraffine-achtige stoffen. Bezoekers van de kust, belangengroeperingen zoals Stichting de Noordzee en politici, allen hebben in toenemende mate aandacht voor deze vorm van zee- en kustvervuiling. Beleidsmakers hebben daarom een groeiende behoefte aan kennis om de milieuproblematiek in kaart te brengen en zo nodig aan te pakken. In principe is het mogelijk dat dergelijke stoffen vanuit scheepstransporten legaal in het zeemilieu terecht komen, omdat de regelgeving onder het MARPOL verdrag het op zee wassen van de ruimen van bulktankers binnen bepaalde grenzen toestaat (MARPOL Annex II). De kosten van schoonmaken van stranden bij vervuiling met paraffine-achtige stoffen liggen bij kustgemeentes doch in ernstiger gevallen bij het Rijk (RWS).

Wageningen Marine Research komt in het langlopend monitoring onderzoek aan plastics in maaginhouden van Noordse Stormvogels voor Rijkswaterstaat, geregeld ook paraffine-achtige stoffen tegen. Dat gebeurt zowel bij strandbezoek voor het verzamelen van dode vogels, als bij het onderzoeken van de maaginhouden. Vanuit deze achtergrond is een voorstel gedaan voor een verkennend onderzoek in het kader van het Kennisbasis onderzoek onder het KB-Programma System Earth Management 2018.

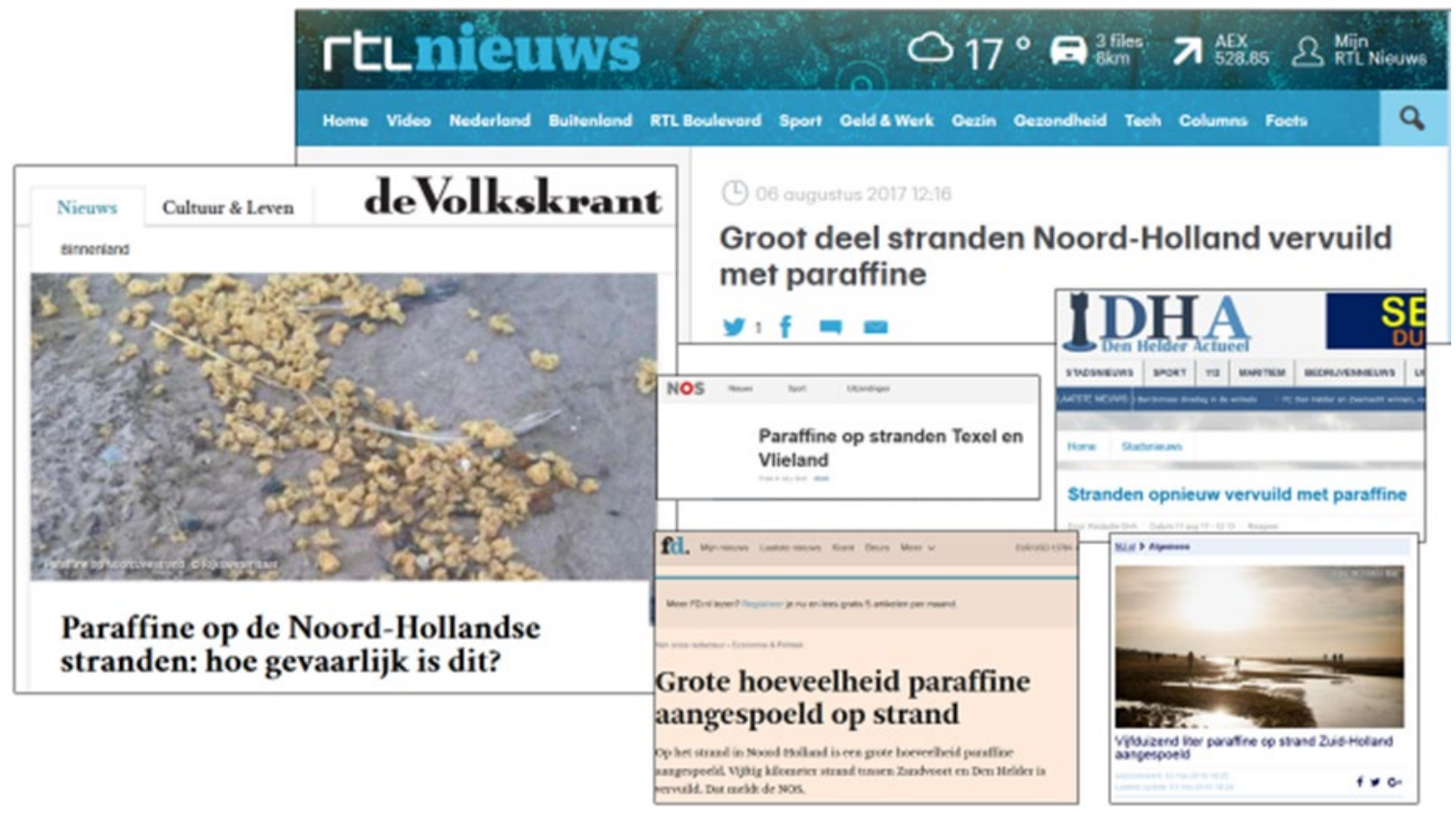

Figuur 2 Media aandacht voor vervuiling van de kust met paraffine.

Figure 2. Media attention for coastal pollution incidents with paraffin-like substances.

Paraffine is een aardolieproduct dat op grote schaal wordt gebruikt voor bijvoorbeeld kaarsen, cosmetica, verpakkingsmateriaal en andere toepassingen. In 2014 werd meer dan 3 miljoen ton wereldwijd geproduceerd en 4\% groei wordt verwacht tot 2022 (Grand View Research 2017). Paraffine wordt in vloeibare vorm via tankschepen vervoerd en mag volgens MARPOL Annex II in kleine hoeveelheden tijdens het schoonmaken van de ladingtanks in zee geloosd worden (MEPC 2004). Resten in laadruimen kunnen bestaan uit een mix van vloeibaar materiaal en verharde korsten en bezinksels. Vloeibaar geloosd materiaal zal veelal door de lagere temperatuur van zeewater samen klonteren in brokken die door wind en stroming op Nederlandse stranden terecht komen. Vergelijkbare transportmethodes en lozingsregels gelden voor andere stoffen, zoals palmolie dat ook in grote hoeveelheden door tankers langs onze kusten wordt vervoerd en in Rotterdam wordt verwerkt. 
Plantaardige oliën worden gebruikt in vele voedselproducten, maar ook als 'biobrandstof' en ook in toepassingen vergelijkbaar met die voor paraffine.

Marine organismes zoals de Noordse Stormvogel (Fulmarus glacialis; Figuur 4), maar ook honden op het strand kunnen aangespoelde brokken paraffine-achtig materiaal inslikken, wat soms dodelijk kan zijn (BBC News 2013). Over de chemische effecten van paraffine op dieren is weinig bekend (Chpt 5 in Roose et al. 2011). Kustgemeentes en/of Rijkswaterstaat (RWS) moeten bij sterk vervuilde stranden kosten maken om deze op te laten ruimen. In de afgelopen tijd heeft toenemende publieke aandacht voor het probleem geleid tot vragen in de tweede kamer (Ministerie van Infrastructuur en Milieu, Beantwoording Kamervragen van het lid Jetten (D66) over de aanhoudende berichten dat er paraffine aanspoelt op de Nederlandse stranden, 5 September 2017).

Plastics in maaginhouden van Noordse Stormvogels worden al vanaf begin jaren 1980 onderzocht (Van Franeker 1985). Sinds 2002, na het uitvoeren van een pilot studie is dit onderzoek uitgegroeid tot een door Rijkswaterstaat mede gefinancierd jaarlijks monitoring programma in het kader van het OSPAR verdrag, en meer recentelijk ten dienste van de Europese KaderRichtlijn Marien (KRM). In de pilot studie (Van Franeker \& Meijboom 2002) werd voorgesteld om naast plastic zwerfafval ook de aangetroffen paraffine-achtige substanties in een monitoringprogramma te betrekken. Echter de aanleiding voor de eerste financiering kwam vanuit de achtergrond van regelgeving t.a.v. de inname door havens van operationeel afval uit de scheepvaart, waaronder huishoudelijke afval, internationaal gereguleerd in MARPOL Annex V. Vervuiling met paraffine en vergelijkbare stoffen werd echter geregeld onder MARPOL Annex II voor bulktransport van chemische stoffen, en werd derhalve niet als een zwerfvuil probleem onderkend. Om budgettaire redenen werd daarom destijds besloten het onderzoek aan paraffine-achtige stoffen niet in de monitoring opdracht mee te nemen.

Sinds dat besluit is de registratie van paraffine-achtige stoffen in de vogelmagen niet formeel voortgezet. Op eigen kosten zijn de basisgegevens wel verzameld voor eventueel later gebruik, doch niet verder in databases verwerkt of geanalyseerd. Gezien de onmiskenbare milieuproblematiek en uiteindelijk onvermijdelijke beleidsvragen zijn ook geregeld monsters van paraffine-achtige substanties uit de vogelmagen en van op strand gevonden mogelijke bronmaterialen verzameld, en in diepvries opgeslagen.

In het najaar van 2017 was de groeiende media- en beleidsaandacht aanleiding voor een voorstel om de verzamelde gegevens en chemische monters te benutten in een verkennend onderzoek binnen het kennisbasis programma System Earth Management 2018. Het voorstel omvatte daartoe de volgende vragen:

1. Hoe vaak en in welke hoeveelheden worden paraffine-achtige substanties in magen van Noordse Stormvogels aangetroffen, en zijn er veranderingen in de loop der tijd waarneembaar?

2. Betreffen lozingen van dit soort materiaal op zee, en de substanties gevonden in vogelmagen vooral paraffine, of spelen ook andere geloosde stoffen, zoals plantaardige vetten, waaronder palmvet een belangrijke rol?

3. Zijn er aanwijzingen dat deze stoffen voor het milieu, dier of mens gevaarlijke toevoegingen bevatten, bijv. uit schoonmaakmiddelen?

Dit voorstel is gehonoreerd onder nummer KB-24-002-036 (WMR projectnummer 43183000 57) en de uitwerking van bovenstaande vragen is voor zover mogelijk binnen de financiële mogelijkheden aangepakt. Er bestaat slechts weinig wetenschappelijke literatuur over dit onderwerp (Dahlmann et al. 1993, Roose et al. 2011). Gezien de expertise van WMR bij monitoring van stormvogels en chemische analyses in marien onderzoek kan dit onderzoek het begin zijn van een mogelijke substantiële bijdrage aan de vereiste kennisbasis. 


\section{$4 \quad$ Materiaal en Methoden}

\subsection{Strandonderzoek}

Tijdens strandbezoeken, al dan niet in het kader van reguliere Beached Bird Surveys van de Nederlandse Zeevogelgroep (Camphuysen 2018), zijn op Texel vanaf 2007 geregeld brokstukjes verzameld van aangetroffen paraffine-achtige of andere verdachte chemische materialen. Stukjes van dit materiaal zijn in glazen containers of aluminiumfolie opgeslagen en in diepvries $\left(-20^{\circ} \mathrm{C}\right)$ bewaard. Aangespoeld materiaal varieert in grootte tussen grote klonten en brokjes in de millimeter schaal die je alleen ontdekt bij heel gedetailleerd onderzoek van zwerfvuil. Voor analyses in dit verkennend rapport zijn, verdeeld over jaren, 32 monsters uitgezocht waarvan ruim voldoende materiaal beschikbaar was.

A.

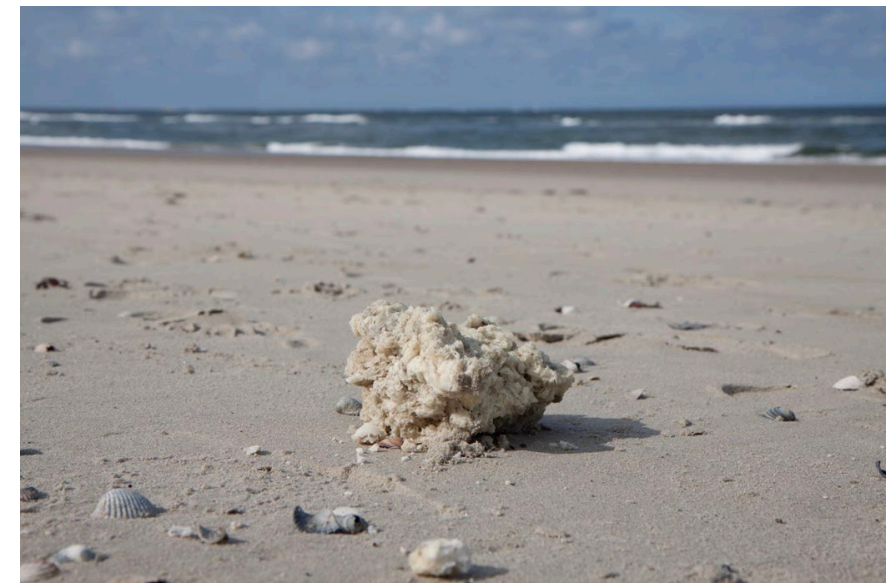

B.

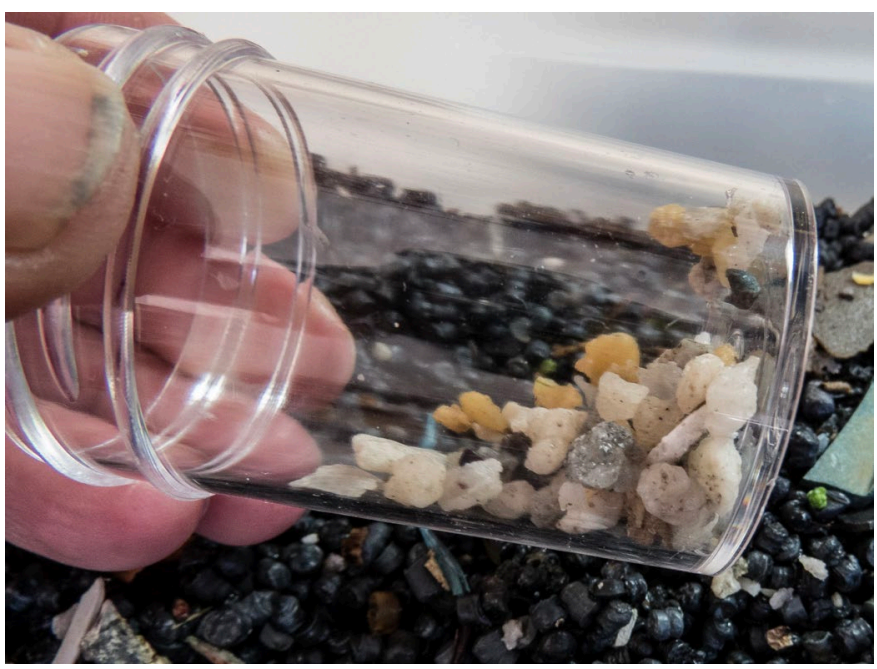

Figuur 3 A. een brok paraffine of palmvet-achtig materiaal op het Texels strand; $B$. diverse types kleine brokjes paraffine of palmvet, aangetroffen bij het uitsorteren van een monster van aangespoelde industriële plastic pellets van het Texelse strand.

Figure 3 A. Lump of paraffin- or palmfat-like material on the beach of the island of Texel. B. tiny bits of a broad range of such materials found while sorting out a sample of industrial plastic pellets beached on Texel. 


\subsection{Stormvogelonderzoek}

De methodes van het monitoringsonderzoek aan plastics in magen van Noordse Stormvogels zijn omschreven in rapporten (Van Franeker 2004; Van Franeker \& Kühn 2018) en in de supplementen van peer-reviewed publicaties (Van Franeker et al. 2011; Van Franeker \& Law 2015). De kern daarvan is dat gebruik wordt gemaakt van op kusten dood gevonden Noordse Stormvogels. Deze worden eerst op uitwendige en inwendige kenmerken onderzocht om zoveel mogelijk van herkomst, doodsoorzaak, lichaamsconditie, leeftijd een geslacht te achterhalen. Vervolgens wordt de maaginhoud onderzocht op de aanwezigheid van plastics, ander zwerfvuil, chemische vormen van vervuiling en voedselresten. De maaginhoud wordt voorzichtig schoon gespoeld met kraanwater over een $1 \mathrm{~mm}$ zeef. Specifiek t.a.v. de bepalingen van klonters minerale olie of paraffine-achtige chemicaliën, worden maaginhouden eerst omgespoeld goed bekeken en daarna voorzichtig gespoeld onder koud water. Eventueel aanwezige brokstukken paraffine-achtig materiaal worden geteld en gewogen en verzameld in glazen snap-cap containers of aluminium folie. Vaak is het materiaal zacht en plakkerig en slechts deels verzamelbaar, in dat geval wordt het materiaal geteld als één brok. Op basis van het gewogen verzamelde deel van dit materiaal wordt geschat hoeveel massa in totaal in de maag aanwezig was. Daarna wordt overgegaan tot meer intensief spoelen van de maaginhoud voor verder onderzoek aan plastics of voedselresten. De verzamelde monsters van paraffine-achtige materialen werden in diepvries $\left(-20^{\circ} \mathrm{C}\right)$ opgeslagen voor latere chemische analyses.

Voor de analyses van frequentie van voorkomen en gemiddeld gewicht van paraffine-achtige stoffen in de stormvogelmagen is gebruik gemaakt van de volledige database van 1101 stormvogels verzameld in Nederland tussen 1979 en 2017. Voor chemische analyses is gebruik gemaakt van 32 monsters uit magen verzameld vanaf 2007.

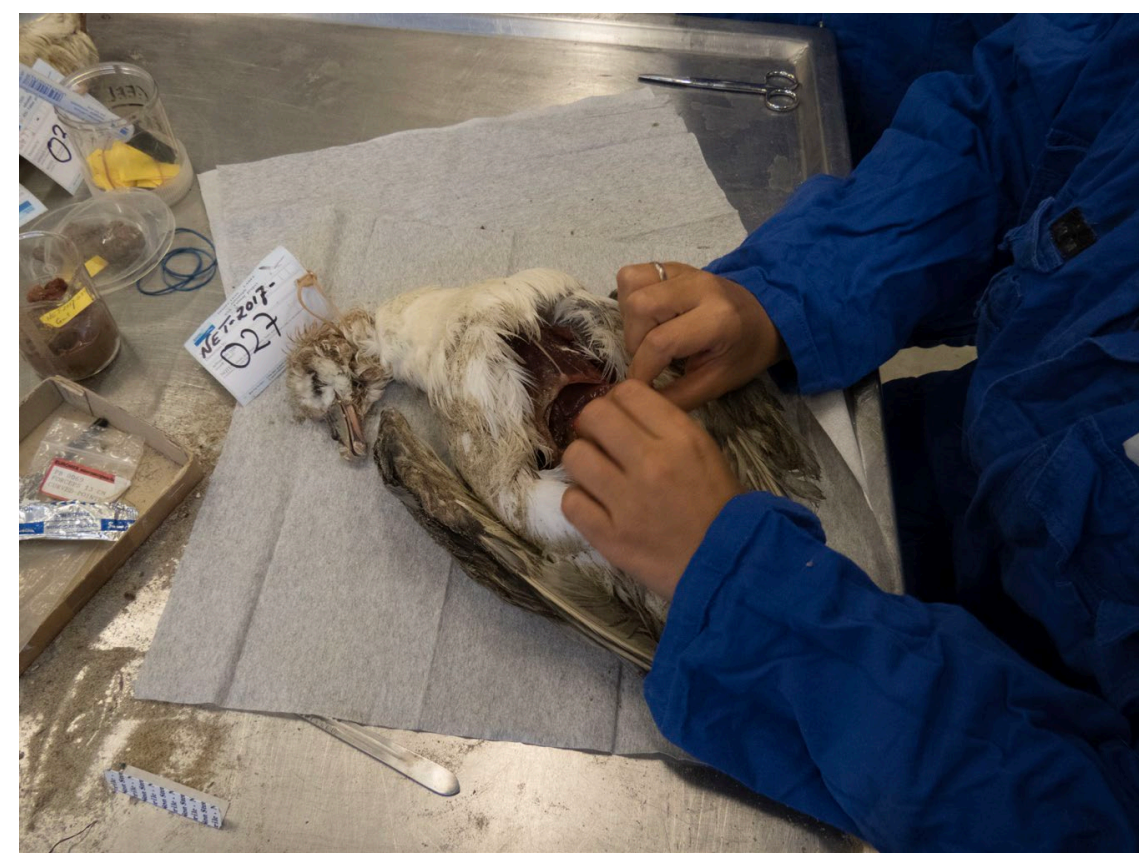

Figuur 4. Bij dissectie van een stormvogel voor het monitoren van plastics in de maaginhoud worden allerlei uitwendige en inwendige kenmerken geregistreerd die informatie verschaffen over bijv. leeftijd, geslacht, conditie, herkomst en mogelijke doodsoorzaak.

Figure 4 During dissection of a fulmar for monitoring of plastics in the stomach, many external and internal characters are recorded that provide information about e.g. age, sex, condition, origin, and potential causes of death. 


\subsection{Chemische analyses}

Paraffine is een mengsel van uit aardolie verkregen alkanen met variërende ketenlengte $\left(\mathrm{C}_{n} \mathrm{H}_{2 n}+2\right)$. Door ruwe monsters op te lossen in hexaan en daarna te fractioneren over neutrale aluminiumoxide worden de vetten en olie verwijderd en blijft een oplossing met alkanen over. Deze oplossing zijn geanalyseerd met een Agilent 6890 gas chromatography-mass spectrometry (GC-MS) uitgerust met een $60 \mathrm{~m}(0.25 \times 0.25) \mathrm{J} \& W$ DB5 kolom. De MS bron temperatuur was $200^{\circ} \mathrm{C}$ en de quadropool 150 ${ }^{\circ} \mathrm{C}$. De monsters zijn splitless geïnjecteerd bij een temperatuur van $320^{\circ} \mathrm{C}$. Het ovenprogramma begon bij $90^{\circ} \mathrm{C}$ gedurende 3 min en vervolgens met $15^{\circ} \mathrm{C}$ naar $320^{\circ} \mathrm{C}$. Tijdens de run is er gemeten in 'full scan' op massa 50-630. Bij de GC-MS analyse is voor paraffine een zeer specifiek alkaan patroon zichtbaar. Bij afwezigheid van dit patroon kan met enige zekerheid gesteld worden dat het monster in ieder geval niet hoofdzakelijk uit paraffine bestond.

Bij een negatief resultaat voor paraffine is een tweede extract geprikt op de GC-MS waarbij er gekeken is naar de onbekende pieken. Hierbij is dan geprobeerd de pieken te identificeren aan de hand van de NIST 2017 Bibliotheek. De aanwezigheid van vetzuren of esters is dan een indicatie dat het hier om bijvoorbeeld palmolie gaat.

\subsection{Analyse van gegevens}

De gegevens van de vogeldissecties en maaganalyses worden in eerste instantie ingevoerd in Excel spreadsheets en vervolgens opgeslagen in een Oracle relationele database. GENSTAT (19th Edition) wordt gebruikt voor statistische toetsen. In het stormvogelonderzoek wordt sinds het verkennend onderzoek (Van Franeker \& Meijboom 2002) gewerkt volgens de inmiddels in OSPAR Guidelines en peer-reviewed literatuur vastgelegde analyse methodes. Dat betekent dat vooral wordt gekeken naar het gewicht van plastics of andere contaminanten, en niet zozeer naar aantallen stukjes. Trends over de tijd worden geanalyseerd door lineaire regressies uit te voeren van log getransformeerd plastic gewicht (of andere materialen) in individuele vogelmagen tegen het jaar van verzamelen van de vogel. De logaritmische transformatie is daarbij noodzakelijk om te rekening te houden met extreme 'uitbijters' en het niet normaal verdeeld zijn van de gegevens. Significantie van correlaties wordt berekend over verschillende periodes: dat kan zijn over de volledige periode van gegevens (sinds 1979), maar de standaard voor analyses ten behoeve van het beleid is in principe om te kijken de trends over de meest recente periode van 10 jaar (in dit rapport 2008-2017). Omdat voor voorspellende modellen de periode van 10 jaar vaak te kort is gebleken wordt sinds de meest recente analyses (Van Franeker \& Kühn 2018) ook de periode 2002 tot heden bekeken. In 2002 startte het 'Save the North Sea' project waarmee alle landen rond de Noordzee stormvogels begonnen te gebruiken voor het graadmeter onderzoek naar plastic zwerfvuil.

In het meest recente rapport (Van Franeker \& Kühn 2018) is een aanvullende methode toegevoegd om veranderingen over de tijd te analyseren en een voorspelling te maken van verwachte ontwikkelingen. Daarin wordt gebruik gemaakt van de jaarlijkse getallen voor de frequentie van voorkomen (\%FO). In plaats van lineaire regressie wordt gebruik gemaakt van een GLM benadering (Generalized Linear Modelling), en een logistische analyse op basis van binomiale verdelingen (bv vogels wel of niet boven de OSPAR doelstelling, of wel of niet met paraffine in de maag) met logit transformatie van de getallen. Een vergelijkbare analyse is sinds lang in gebruik voor de OSPAR monitoring van beoliede vogels op kusten (cf. Camphuysen 2018).

Verschillen in gewicht aan plastic of paraffine tussen bijvoorbeeld gebieden of sexes, of leeftijdsgroepen worden getoetst in Genstat door wederom data van individuele vogels te gebruiken in een negatief binomiale GLM procedure (Generalized Linear Model) waarin gebied, sexe, leeftijdsgroep wordt gebruikt als een factor die wel of niet wordt in beschouwing wordt genomen en de verschillen tussen de modellen worden getoetst met gebruik van een likelihood ratio test (Venables \& Ripley 2002; van Franeker et al. 2011).

Tot slot worden verschillen in Frequentie van voorkomen (\%FO) van plastics of paraffine tussen twee datasets soms geanalyseerd door middel van de '2-sample z-test' met tweezijdige benadering zoals beschreven door Sergeant (2019), daarbij gebruik makend van de website:

http://epitools.ausvet.com.au/content.php?page=z-test-2.

In alle toetsen hanteren we $p<0.05$ als vereist niveau voor statistische significantie. 


\section{$5 \quad$ Resultaten}

\subsection{Identificatie van op strand gevonden paraffine- of palmvet achtige substanties.}

Voor dit verkennend onderzoek zijn 32 op het strand verzamelde stukken paraffine of palmvet-achtig materiaal geanalyseerd. De meeste stukken zijn verzameld tijdens Beached Bird Surveys op Texel Een kleiner aantal komt van andere locaties zoals de kwelders langs de Fries-Groninger kust. De gevonden brokken variëren in het algemeen in kleur tussen wittige of vies grijs en geelbruin tot oranjeachtig.

A.

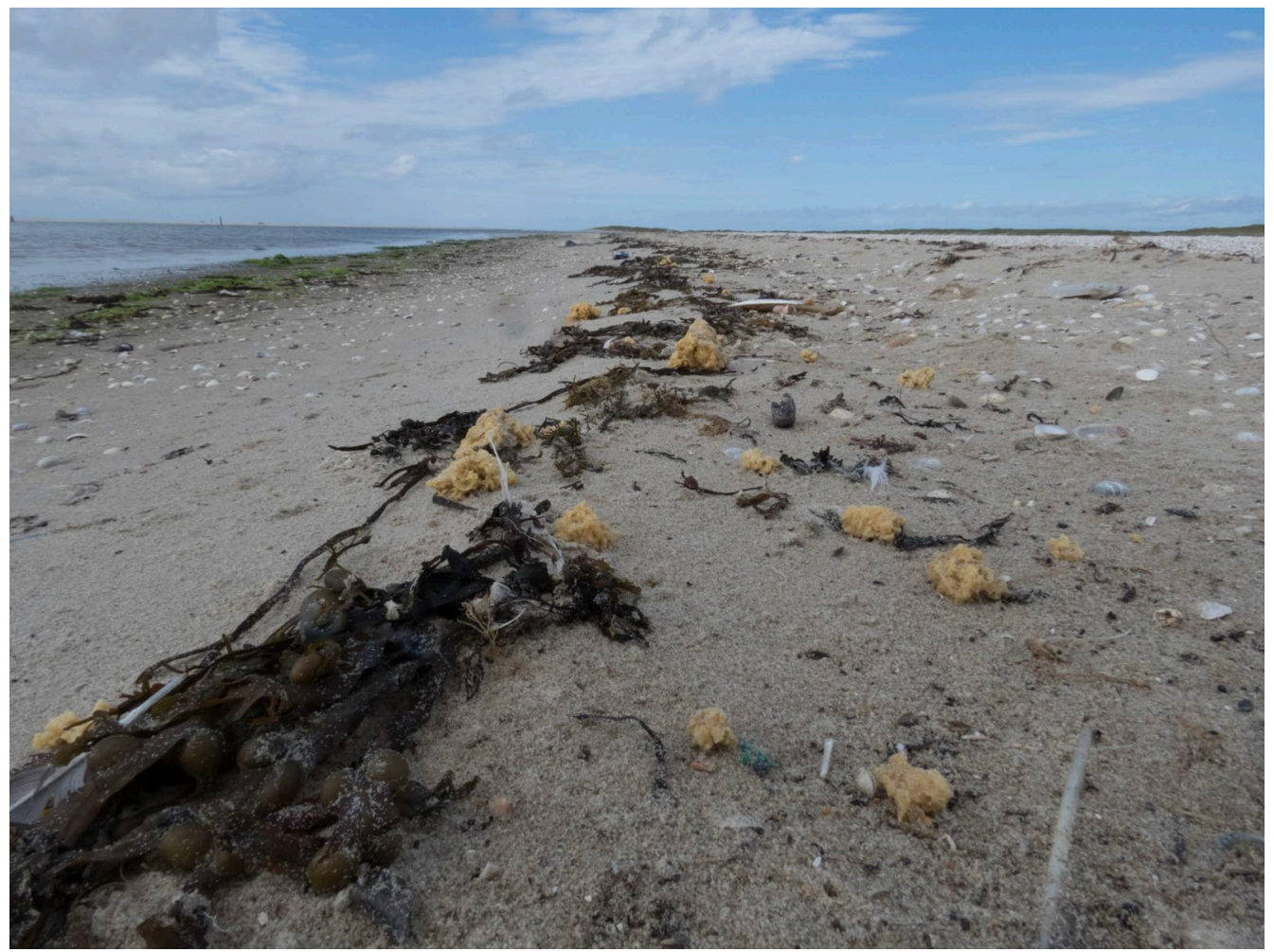

B.

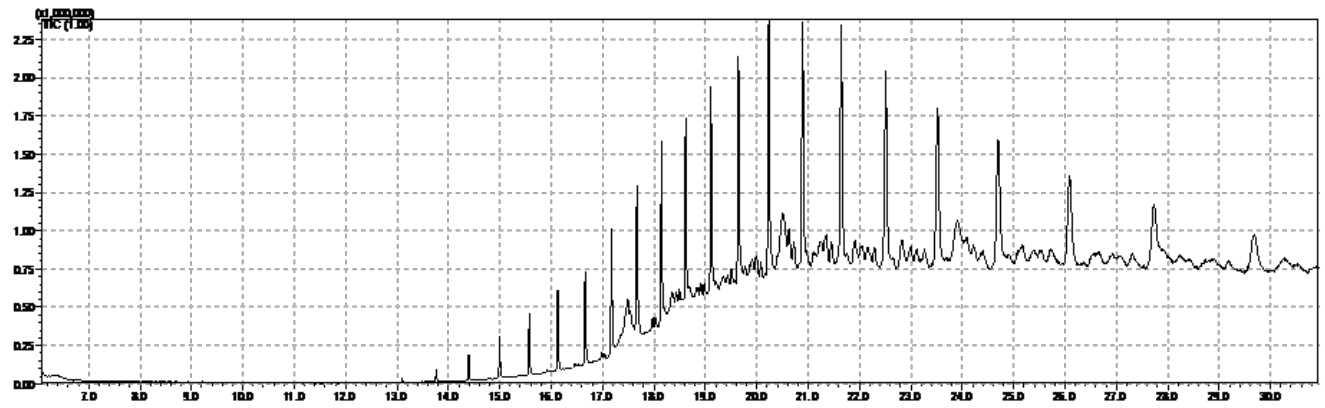

Figuur 5 A. Licht-bruingele zachte brokken materiaal, verzameld onder nr PAR-20170811-02 op de Hors op Texel, werden ingeschat als vermoedelijk palmvet. B. De latere chemische analyse toont echter sterke alkaan pieken die het materiaal als een paraffine-achtige stof identificeren.

Figure 5 A. lightbrown to yellowish soft lumps of material collected as sample PAR-20170811-02 on the south beach of Texel, were believed to probably be palmfat. B. Subsequent chemical analysis showed strong alkane peaks identifying this material as a paraffin. 
Tabel 1 Geanalyseerde monsters van paraffine of palmvet-achtige materialen, verzameld langs de Nederlandse kust, over de periode 2007-2017. Analyses wijzend op paraffine in

ongekleurde regels; plantaardige vetten in groen; onzekere bepalingen in blauw.

Table 1 Samples of paraffin-or palmfat-like substances from the Dutch coast over the period 2007-2017. Identification as paraffin shown in non-coloured rows, vegetable fats in green; and uncertain types in blue.

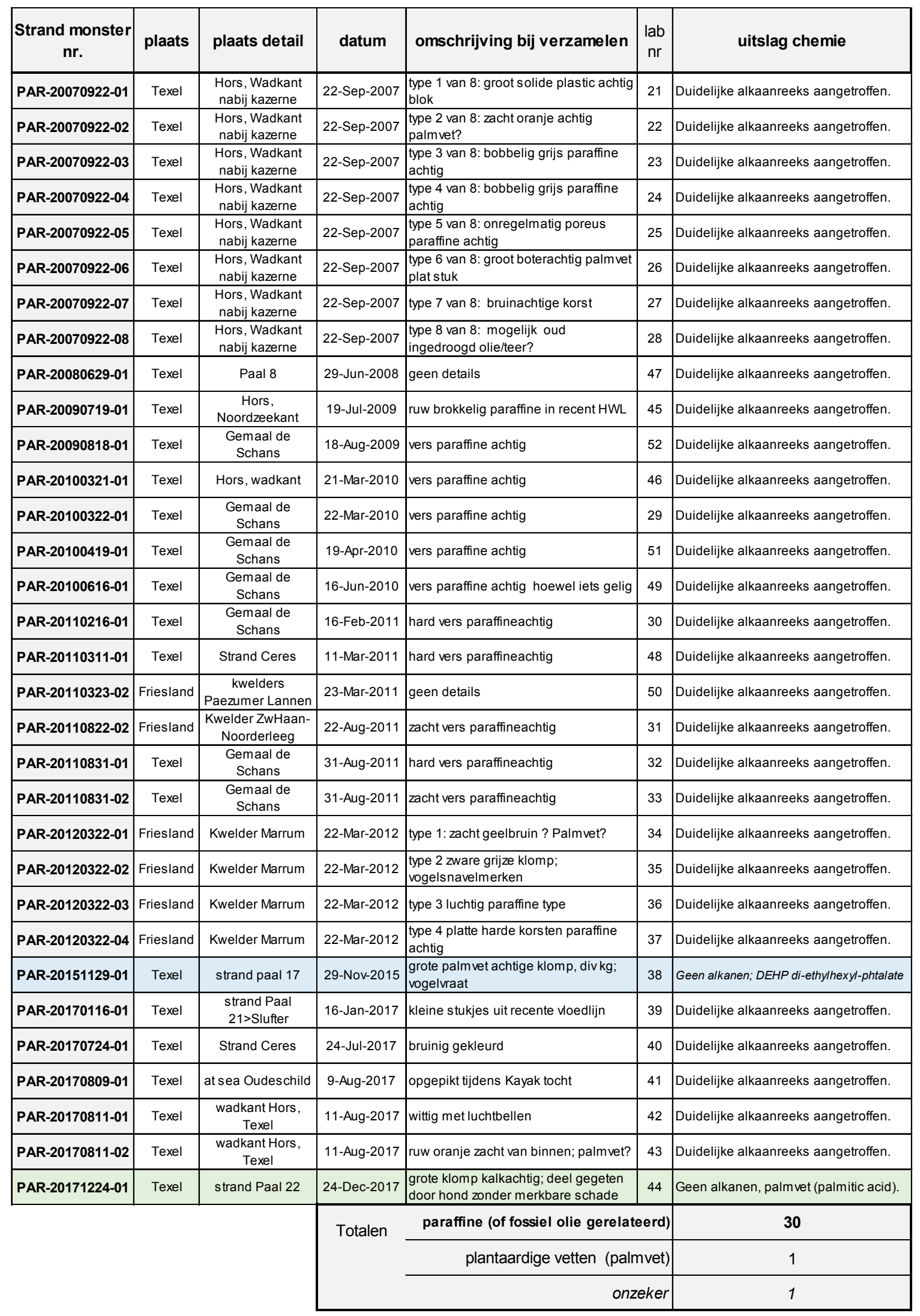


Enigszins onverwacht bleken 30 van de 32 verzamelde stukken (94\%) sterke alkaanpieken te vertonen als duidelijke aanwijzing dat bijna al onze strandmonsters uit paraffine-achtige stoffen bestonden. De verwachting van de auteurs dat de geregeld aangetroffen geelbruine en oranje kleuren van aanspoelsels op palmvetten zouden wijzen, bleek dus onterecht.

In de strandbemonstering waren dus slechts twee samples aanwezig zonder duidelijke alkaanpieken. Daarvan bevatte er één duidelijke aanwijzingen voor palmvet. Het andere sample bevatte echter ook geen traceerbare palmvet bestanddelen, maar toonde wel duidelijke aanwezigheid van Di-ethylhexylphtalate (DEHP) een weekmaker voor plastics.

Twee donkere brokken materiaal uit een vroege bemonstering (nrs PAR-20070922-01 en 08) suggereren dat andere ruwe oliederivaten vergelijkbare alkaan pieken geven. Het eerste sample was hard en bijna glasachtig. Het laatste sample was mogelijk een zeer oude ingedroogde teerklomp.

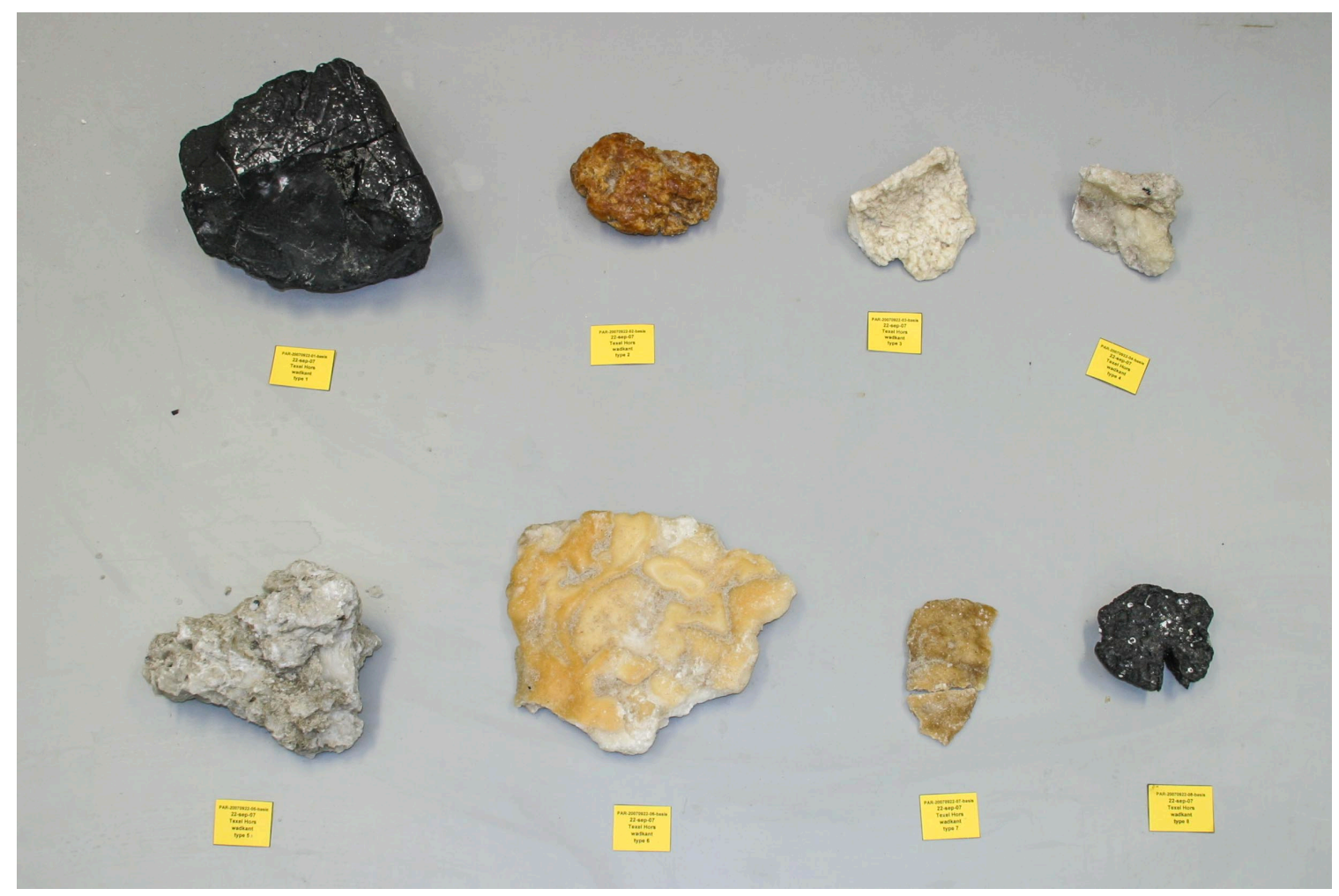

Figuur 6 Strandmonsters PAR-20070922-01 t/m 08 tonen een rijke variatie aan vorm en uiterlijk, van wit tot bruingeel, en van luchtig tot compact. Alle acht types leverden in de chemische analyses heldere alkaan pieken, wijzend op paraffine en mogelijk andere aan ruwe olie verwante stukken materiaal.

Figure 6 Beach samples PAR-20070922-01 to 08 show strong variability in shape and appearances, from white to yellowish brown and from hard solid to air-bubbled soft materials. All eight types revealed strong alkane peaks in the analysis, indicating paraffin or other materials closely related to mineral oil. 


\begin{tabular}{|c|c|c|c|c|c|}
\hline \multirow[b]{2}{*}{ 1979-2017 } & \multirow[b]{2}{*}{$\mathbf{n}$} & \multirow[b]{2}{*}{$\%$ FO } & \multirow[b]{2}{*}{$\%>0.1 \mathrm{~g}$} & \multicolumn{2}{|c|}{ mass (gram) } \\
\hline & & & & avg \pm se & $\max$ \\
\hline All & 1101 & $21 \%$ & $11 \%$ & $0.81 \pm 0.18$ & 110 \\
\hline Adults & 554 & $23 \%$ & $10 \%$ & $0.66 \pm 0.21$ & 67 \\
\hline non adults & 520 & $20 \%$ & $12 \%$ & $0.97 \pm 0.29$ & 110 \\
\hline
\end{tabular}

Tabel 2 Aanwezigheid van paraffine-of palmvet-achtig materiaal in 1101 Noordse Stormvogels van de Nederlandse kust over de periode 1979 tot en met 2017. De tabel toont Frequentie van voorkomen (\%FO) van verdachte materialen, het percentage vogels met meer dan 0.1 gram (\%>0.1g) van zulk materiaal, het gemiddeld gewicht met standaardfout (avg \pm se) en de maximum hoeveelheid aangetroffen in een enkele maag (max). Verschillen tussen leeftijdsgroepen zijn niet significant.

Table 2 Abundance of paraffin-or palmfat-like substances in 1101 Northern Fulmars from the Dutch coast over the period 1979 to 2017. The table shows Frequency of occurrence (\%FO), the percentage of birds having more than $0.1 \mathrm{~g}$ of such substance, the average mass (avg $\pm \mathrm{se}$ ) and the maximum mass encountered in a single stomach (max). Differences between age groups were not significant. 


\subsection{Frequentie van voorkomen en hoeveelheid paraffine- of palmvet achtige substanties in de magen van in Nederland gevonden Noordse Stormvogels}

Over de periode 1979 tot en met 2017 zijn in totaal 1101 magen van in Nederland aangespoelde Noordse Stormvogels onderzocht op de aanwezigheid van plastics, ander zwerfvuil, mogelijk chemische vervuiling en natuurlijke voedselresten. De aanwezigheid van paraffine-achtig materiaal werd na de pilotstudy (Van Franeker \& Meijboom 2002) niet meegenomen voor de formele monitoring voor RWS en later OSPAR en KRM, maar werd wel in basisgegevens genoteerd en waar mogelijk werden monsters bewaard. Deze ongebruikte gegevens zijn nu voor dit BO onderzoek aan de databases toegevoegd en geanalyseerd.

Gerekend over de volledige dataset bevatte $21 \%$ van de 1101 onderzochte magen restanten van paraffine-achtige materialen. Soms betrof dat slechts kleine klontjes, maar in $11 \%$ van alle magen woog het verdachte chemische materiaal meer dan 0.1 gram. Sommige magen waren compleet gevuld met paraffine-achtig materiaal. Zie voor een extreem voorbeeld de dissectie die werd gefilmd voor de documentaire 'Any Waste Any Time' over de havenontvangstinstallaties (HOI's) van het Rotterdams Havenbedrijf. Deze is te vinden op https://www.youtube.com/watch?v=isb8zJtZ7WQ. Het fragment over de dissectie van de Noordse Stormvogel start op ongeveer minuut 8 van de documentaire.

De maximaal aangetroffen maaginhoud van paraffine-achtig materiaal in een stormvogel was 110 gram. Dergelijke extremen beïnvloeden het rekenkundig gemiddeld gewicht van paraffine-achtige stof. Gemiddeld over alle 1101 stormvogels zat er ruim 0.8 gram paraffine-achtige materialen in de magen.

Omdat bij de hoeveelheid plastic in stormvogelmagen een duidelijk verschil zichtbaar is tussen verschillende leeftijdsgroepen, zijn in tabel 2 leeftijdsafhankelijke resultaten ook weergegeven voor paraffine-achtige stoffen. Bij plastics hebben jongere vogels meer plastic gewicht in de maag dan de volwassen dieren. Door extreme invloed van outliers geeft onze standaard test voor groepsvergelijking aan dat een leeftijdstoets op gewichten van paraffine niet mogelijk is. Er is een suggestie dat jongere vogels meer paraffine-achtige stoffen in de maag hebben, zoals misschien ook gedacht zou kunnen worden uit tabel 2, waarin adulte vogels gemiddeld $0.66 \mathrm{~g}$ paraffine in de maag hebben, en jongere dieren $0.97 \mathrm{~g}$. Maar van die laatste waarde is $0.21 \mathrm{~g}$ te danken aan de bijdrage van de enkele vogel met $110 \mathrm{~g}$ paraffine-achtige materiaal in de maag. In frequentie van voorkomen is er geen significant verschil waarneembaar tussen de magen van volwassen en niet-volwassen vogels (z-test op \%FO $\mathrm{p}=0.4696$; z-test op \%>0.1g $\mathrm{p}=0.2515$ ).

In de lange dataserie is geen significante trend over de tijd waarneembaar in de hoeveelheid ingeslikte paraffine-achtige stoffen. In het plastic onderzoek is, om eventuele patronen over de tijd visueel zichtbaar te maken, gekozen voor figuren die gebaseerd zijn op 'lopende' 5-jaarsgemiddeldes. Daarmee worden eventuele verschillen tussen jaren door de aanwezigheid van uitschieters of kleinere monstergrootte visueel meestal gladgestreken. Zulke weergaves hebben echter geen statistische betekenis. In het geval van de paraffine werkt zelfs het gebruik van deze lopende gemiddeldes niet goed als gevolg van één zeer extreme waarde van een vogel met 110 gram paraffine-achtige substanties in de maag (Figuur 7).

Onze in het plastic onderzoek gestandaardiseerde toets-methode die gebruik maakt van alle individuele waardes geeft over geen enkele tijdsperiode een significante trend in aangetroffen paraffine gewicht (1979-2017, 1101 magen $\mathrm{p}=0.416 ; 2002-2017,715$ magen $\mathrm{p}=0.635 ; 10$ jaarsperiode 2008-2017, 349 magen $p=0.267$ ).

Een in het plastic onderzoek recent opgestarte methode kijkt naar jaarcijfers voor de frequentie van voorkomen. Ook deze geven geen significante patronen in het voorkomen van paraffine-achtige stoffen in de stormvogelmagen (1979-2017 $p=0.92 ; 2002-2017 p=0.135 ; 10$-jaarsperiode 2008-2017 $\mathrm{p}=0.081$ ). De trendlijn is in al deze toetsen wel negatief, en komt dus in de meest recente 10-jaars evaluatie in de buurt van significantie. Deze trend wordt ook gesuggereerd in de weergave van lopende 5-jaars frequenties in Figuur 8. 

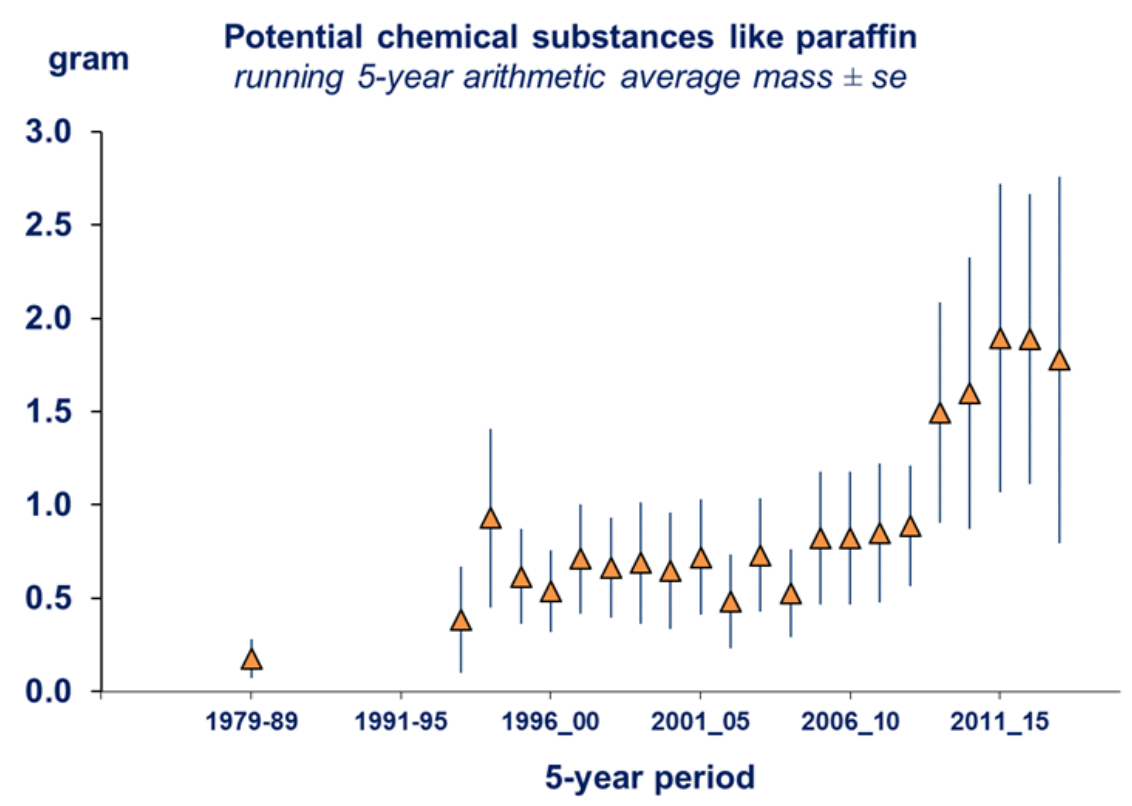

Figuur 7 Gewicht van paraffine- of palmvet-achtige substanties in magen van Noordse Stormvogels vanaf de start van het monitoringssysteem, in lopende 5-jaarsgemiddeldes, met standaardfout van de gemiddeldes (jaren eerder dan 1990 in één getal samengevoegd). Deze representatie heeft geen statistische waarde. De hoge gemiddeldes in recente 5jaarperiodes zijn het gevolg van één extreme uitbijter van 110 gram paraffine in de maag van een vogel uit 2013, geïllustreerd door een zeer grote standaardfout.

Figure 7 Mass of paraffin- or palmfat-like substances in stomachs of Northern Fulmars since the start of the monitoring system, in running 5-year averages with standard error (years before 1990 given as a single value). This visualisation has no statistical value. High averages in recent years caused by an outlier of $110 \mathrm{~g}$ paraffin in a single bird found in 2013. Large standard errors illustrate the problem.

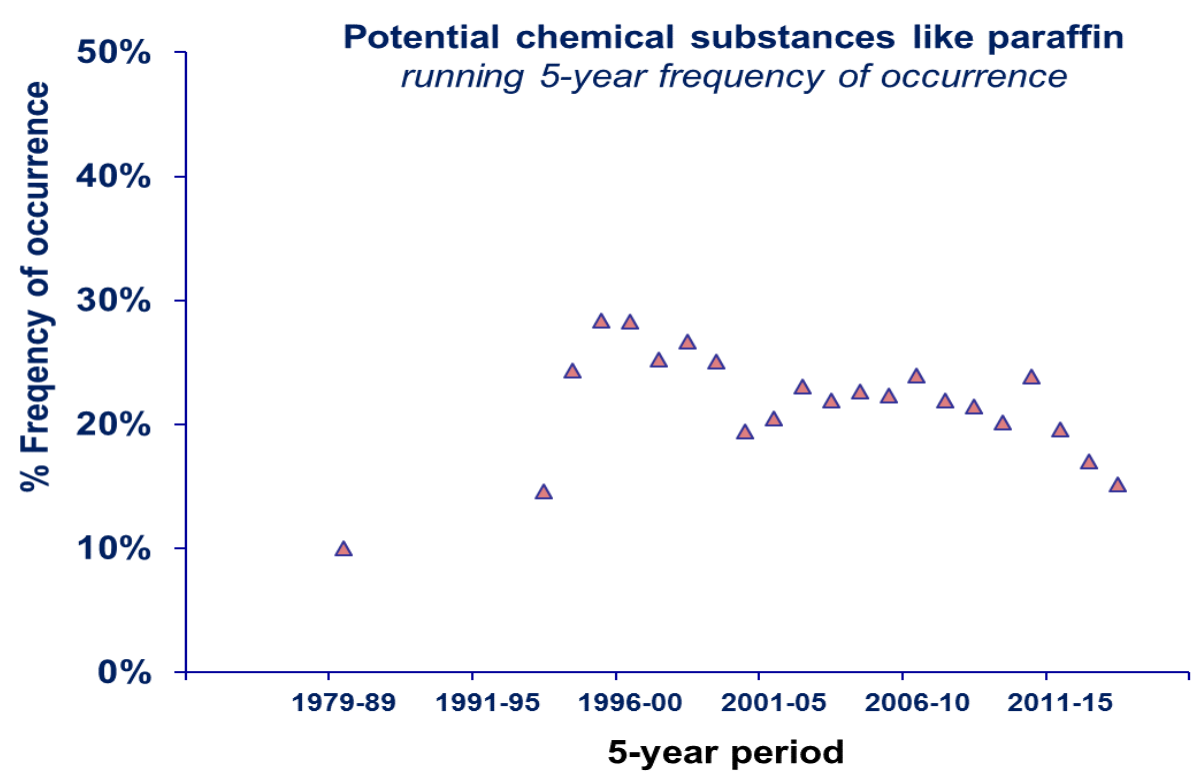

Figuur 8 Lopende 5-jaarsgemiddeldes voor de frequentie van voorkomen van paraffine-achtige stoffen in magen van in Nederland gevonden Noordse Stormvogels. Jaren voorafgaand aan 1990 zijn in één getal samengevoegd.

Figure 8 Running 5-year averages for the frequency of occurrence of paraffin-or palmfat-like materials in stomachs of fulmars beached in the Netherlands. All data prior to 1990 combined in a single datapoint. 


\subsection{Identificatie van paraffine-of palmvet achtige substanties in de magen van in Nederland gevonden Noordse Stormvogels}

In deze verkennende studie werden chemische analyses voor nadere bepalingen aan paraffine- of palmvet achtige materialen uitgevoerd over in totaal 32 monsters van in Nederland gevonden Noordse Stormvogels. Daaronder 30 monsters van chemisch verdacht ogende stoffen uit de maag, één monster uit een opgezwollen darm, en één monster van aan de buikveren plakkend materiaal.

A

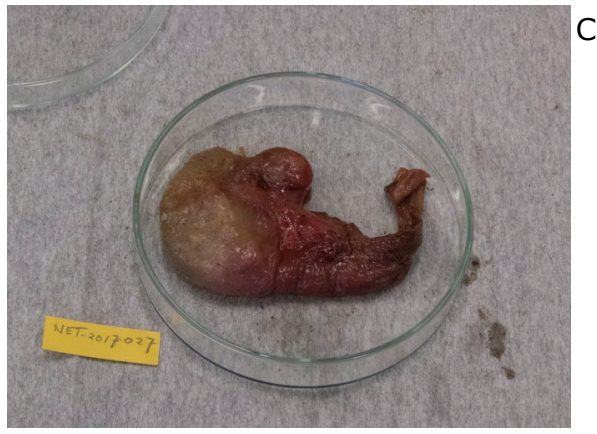

B
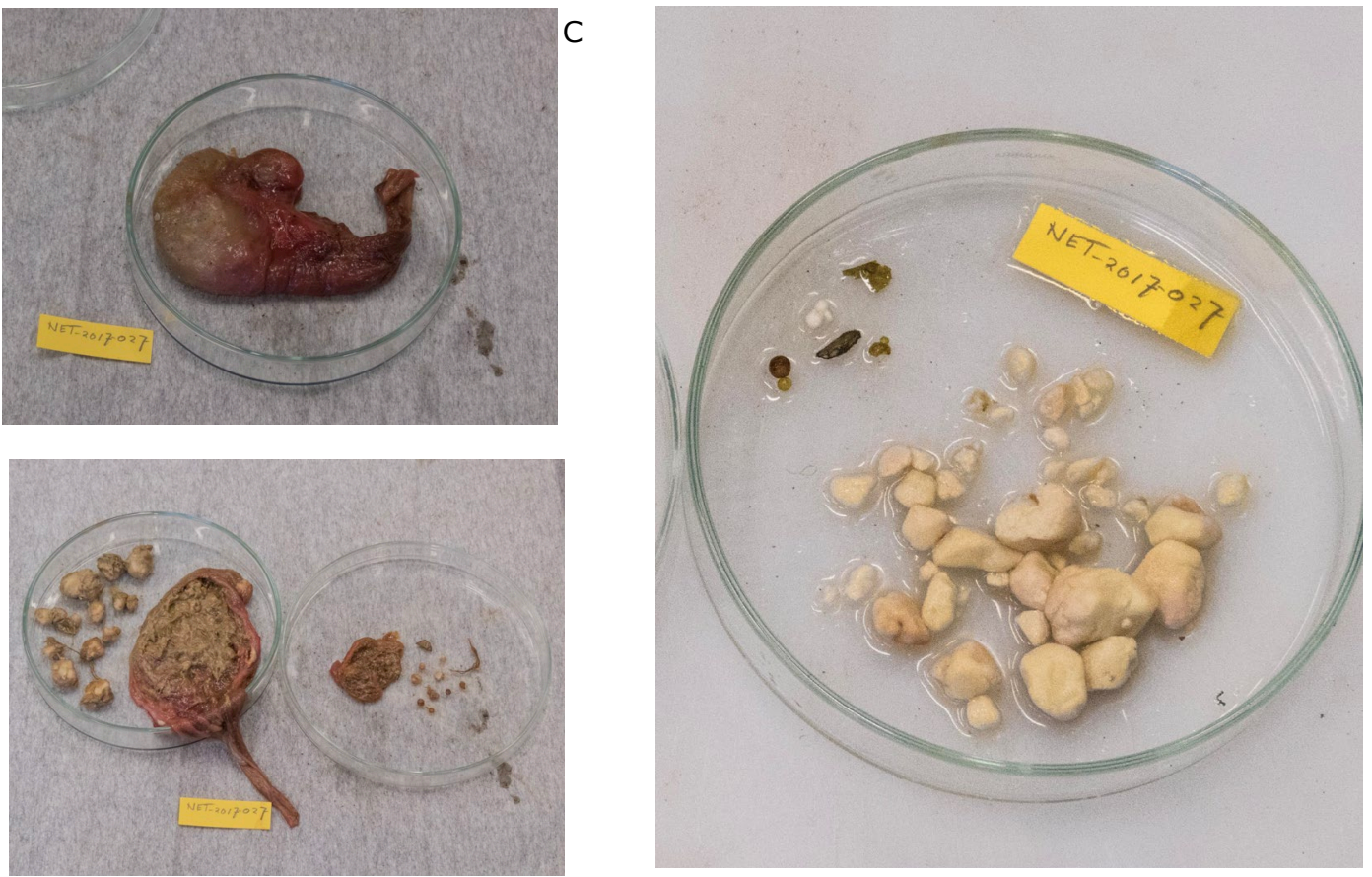

D

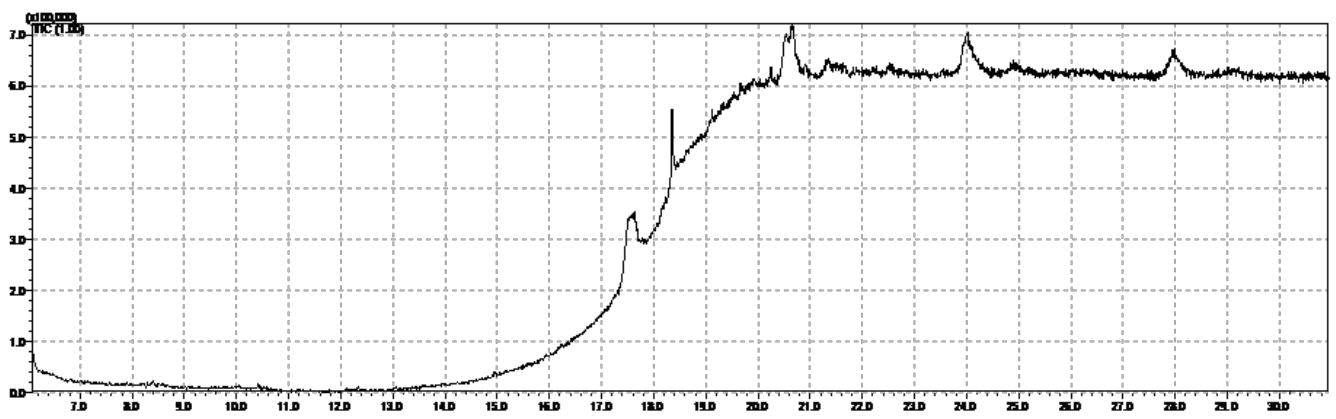

Figuur 9 De maag van stormvogel NET-2017-027 stond bol van chemisch verdacht materiaal (A), deels in klonten, deels als zachter vormloos materiaal (B). Na voorzichtig koud spoelen (C) toonden analyses geen duidelijke alkaanreeks (D). In het ruwe extract werd wel dipalmitin aangetroffen, wijzend op palmolie, maar verdere identificatie was niet mogelijk.

Figure 9 The stomach of fulmar NET-2017-027 was heavily filled with chemically suspect material (A), partly in lumps, partly in softer components (B). After careful cold rinsing (C) the chemical analysis showed absence of alkanes (D). However, the next step of analysis found dipalmitin, evidencing palm oil. Further detail was not possible. 
Tabel 3 Analyses van chemisch verdachte materialen gevonden bij een selectie van in Nederland aangespoelde Noordse Stormvogels (30 monsters uit magen, 1 uit darm en 1 uit veren; periode 2007 tot 2018). Conditie weergegeven op een schaal 0 (totaal vermagerd) tot 9 (uitstekende conditie) op basis van codes voor borstspier conditie, onderhuidse vetreserves en ingewand vet. Analyses wijzend op paraffine in ongekleurde regels; plantaardige vetten in groen; onzekere bepalingen in blauw.

Table 3 Analyses of chemically suspect substances from a selection of fulmars beached in the Netherlands (30 samples from stomachs, one from intestines, and one from feathers). Body condition of the birds shown in scale 0 (totally emaciated) to 9 (excellent condition) on the basis of codes for condition of breast muscle, subcutaneous fat and intestinal fat. Identification as paraffin shown in non-coloured rows, vegetable fats in green; and uncertain types in blue.

\begin{tabular}{|c|c|c|c|c|c|c|c|c|c|c|}
\hline $\begin{array}{c}\text { N. Stormvogel } \\
\text { monster } \mathrm{nr}\end{array}$ & vindplaats & datum & $\begin{array}{l}\text { con- } \\
\text { ditie }\end{array}$ & sex & $\begin{array}{c}\text { leef- } \\
\text { tijd }\end{array}$ & $\begin{array}{l}\text { monster } \\
\text { gewicht } \\
\text { (g) }\end{array}$ & $\begin{array}{l}\text { monster } \\
\text { uit: }\end{array}$ & omschrijving & $\begin{array}{c}\text { lab } \\
\text { nr }\end{array}$ & uitslag chemie \\
\hline NET-2007-005 & $\begin{array}{l}\mathrm{NH} ; \mathrm{Kmp} 18 ; \\
\text { St.Maartenszee }\end{array}$ & 29-Jan-2007 & 1 & $\mathrm{~F}$ & $A D$ & 3.0 & maag & grijzige modder & 1 & $\begin{array}{l}\text { onduidelijke mix van plantaardige en/of dierlijke vetten } \\
\text { Piek van 2, 6, 10-Trimethyl hexadecaan }\end{array}$ \\
\hline NET-2007-013 & $\mathrm{NH}$; Hargen & 27-Jun-2007 & 2 & $\mathrm{~F}$ & JU & 1.0 & maag & grijzige modder & 64 & trilaurin, vermoedelijk te linken aan plantaardige vetten \\
\hline NET-2007-030 & $\mathrm{NH} ; \mathrm{Kmp} 2 \mathrm{O}$; Strand Petten & 11-Sep-2007 & 1 & $\mathrm{~F}$ & $A D$ & $\mathrm{x}$ & darm & $\begin{array}{l}\text { gele plakkerige stof uit } \\
\text { gezwollen darm }\end{array}$ & 2 & heel licht spoor paraffine, maar massa onbekende stof \\
\hline NET-2008-012 & $\begin{array}{l}\mathrm{NH} ; \mathrm{Kmp} 17 ; \\
\text { St.Maartenszee }\end{array}$ & 23-Jun-2008 & 0 & $\mathrm{~F}$ & IM & 1.4 & maag & vetachtige brokken & 3 & vetten, waaronder palmvet \\
\hline NET-2009-016 & $\begin{array}{l}\text { Texel; Noordzeestrand } \\
\text { Hors paal 7-10 }\end{array}$ & 6-Jan-2009 & 1 & M & AD & 4.4 & maag & verdacht materiaal & 4 & heel licht spoor paraffine, massa onbekende stof \\
\hline NET-2009-052 & \begin{tabular}{|l|} 
Ameland strand \\
Ballum $<>\mathrm{De} \mathrm{Hon}$
\end{tabular} & 9-Jan-2009 & 2 & $\mathrm{~F}$ & $A D$ & 0.3 & maag & $\begin{array}{l}\text { korrelig paraffineachtig } \\
\text { materiaal }\end{array}$ & 5 & Duidelijke alkaanreeks wijst op paraffine \\
\hline NET-2010-016 & $\begin{array}{l}\text { Vieland; Viehors; NSO } \\
4053\end{array}$ & 15-Mar-2010 & 0 & $\mathrm{~F}$ & AD & 0.01 & maag & $\begin{array}{l}\text { kleine stukjes paraffine-achtig } \\
\text { materiaal }\end{array}$ & 6 & $\begin{array}{l}\text { onduidelijke mix van plantaardige en/of dierlijke vetten } \\
\text { (vis?). Piek van 2, 6, 10-Trimethyl hexadecaan }\end{array}$ \\
\hline NET $-2010-020$ & TX; Hors & 10-Jul-2010 & 0 & M & IM & 1.0 & maag & $\begin{array}{l}\text { kleine stukjes paraffine-achtig } \\
\text { materiaal }\end{array}$ & 7 & Duidelijke alkaanreeks wijst op paraffine \\
\hline NET-2010-024 & Texel; Ceres strandje & 8-Feb-2010 & 3 & M & JU & 2.4 & maag & meerdere brokjes & 8 & Duidelijke alkaanreeks wijst op paraffine \\
\hline NET-2010-029 & \begin{tabular}{|l|} 
TX14; Texel \\
Noordzeestrand paal 14
\end{tabular} & 17-Mar-2010 & 9 & M & JU & 10.0 & maag & $\begin{array}{l}\text { oranje palmolie-achtige } \\
\text { modder }\end{array}$ & 9 & o.a. plantaardig vet (grape seed oil) \\
\hline NET-2010-036 & $\begin{array}{l}\text { Ameland11; Nzstrand } \\
\text { kmpaal 11; NSO } 5069\end{array}$ & 18-Jun-2010 & 1 & $\mathrm{~F}$ & $A D$ & 0.6 & maag & paraffine-achtig materiaal & 10 & Duidelijke alkaanreeks wijst op paraffine \\
\hline NET-2010-038 & $\begin{array}{l}\text { Duindamse Slag; ten N } \\
\text { van Noordwijk; NSO } 2024\end{array}$ & 31-Jan-2010 & 1 & $\mathrm{~F}$ & JU & 1.3 & maag & paraffine-achtig materiaal & 59 & palmvetten \\
\hline NET-2012-009 & $\begin{array}{l}\text { NHpl } 17 \text { Petten- } \\
\text { Callantsoog NSO } 3035\end{array}$ & 12-Jan-2012 & 1 & M & $2 Y$ & 0.3 & maag & wit paraffine-achtig brok & 11 & Duidelijke alkaanreeks wijst op paraffine \\
\hline NET-2012-017 & $\begin{array}{l}\text { NHpl } 25 \text { Hondsbossche } \\
\text { Zeewering NSO } 3034\end{array}$ & 23-Jan-2012 & 6 & $\mathrm{~F}$ & JU & 11.3 & maag & wit paraffine-achtig materiaal & 12 & palmvetten \\
\hline NET-2012-028 & $\begin{array}{l}\text { Westkapelle Walcheren } \\
\text { Zeeland NSO } 1003\end{array}$ & 10-Jan-2012 & 1 & M & $A D$ & 15.3 & maag & wit paraffine-achtig brokken & 58 & geen duidelijk indentificeerbare stoffen \\
\hline NET-2012-040 & \begin{tabular}{|l|} 
Texel Slufter-Vuurtoren \\
NSO 4043
\end{tabular} & 28-Jan-2012 & 1 & UNK & UNK & 14.2 & maag & wittig paraffine-achtig materiaal & 13 & Duidelijke alkaanreeks wijst op paraffine \\
\hline NET-2012-067 & $\begin{array}{l}\text { Ouddorp Goedereede } \\
\text { Zeeland NSO } 1012\end{array}$ & 16-Feb-2012 & 1 & $\mathrm{~F}$ & $\mathrm{JU}$ & 0.5 & maag & paraffine-achtig materiaal & 54 & Duidelijke alkaanreeks wijst op paraffine \\
\hline NET-2012-071 & \begin{tabular}{|l|} 
Badstrand Vissingen \\
Zeeland NSO 1002 \\
\end{tabular} & 18-Feb-2012 & 2 & M & IM & 0.4 & maag & paraffine-achtig materiaal & 14 & palmvetten \\
\hline NET-2012-072 & $\begin{array}{l}\text { Kalootstrand Borssele } \\
\text { Zeeland near NSO } 1002\end{array}$ & 25-Jan-2012 & 0 & M & JU & 0.1 & maag & $\begin{array}{l}\text { wittig chemisch-achtig } \\
\text { materiaal }\end{array}$ & 55 & onzekere vetten (methyl oleate) \\
\hline NET-2012-083 & \begin{tabular}{|l} 
Ameland Paal 23 NSO \\
5068
\end{tabular} & 5-Jun-2012 & 1 & $\mathrm{~F}$ & IM & 0.5 & maag & vieze vettige massa & 15 & palmvetten \\
\hline NET-2013-003 & \begin{tabular}{|l|} 
Texel paal 12 \\
Hoornderslag-Westerslag
\end{tabular} & 18-Sep-2013 & 1 & $\mathrm{~F}$ & JU & 35.0 & maag & paraffine-achtig materiaal & 61 & geen duidelijk indentificeerb are stoffen \\
\hline NET-2013-004 & \begin{tabular}{|l|} 
Texel paal 26 Slufter- \\
Vuurtoren NSO 4043 \\
\end{tabular} & 17-Sep-2013 & 2 & $\mathrm{~F}$ & JU & 110.0 & maag & $\begin{array}{l}\text { grote massa palmolie-achtig } \\
\text { materiaal }\end{array}$ & 62 & geen duidelijk indentificeerb are stoffen \\
\hline NET-2015-010 & \begin{tabular}{|l}
$\begin{array}{l}\text { Texel paal } 24 \text { zuidkop } \\
\text { slufter }\end{array}$ \\
\end{tabular} & 19-Apr-2015 & 1 & $\mathrm{~F}$ & JU & 0.0 & maag & wit wasachtig materiaal & 53 & Duidelijke alkaanreeks wijst op paraffine \\
\hline NET-2015-016 & Zeeland Westkapelle & 6-Sep-2015 & 0 & M & JU & 0.8 & maag & paraffine-achtig materiaal & 57 & onzekere vetten (stearine) \\
\hline NET-2015-018 & Petten strand kmp 22 & 24-Sep-2015 & 2 & M & JU & $\mathrm{x}$ & veren & paraffin of palmolie in de veren & 63 & lauric acid (kokos olie); geen zulk materiaal in de maag \\
\hline NET-2015-021 & Texel paal 7 & 3-Dec-2015 & 4 & M & JU & 40.0 & maag & $\begin{array}{l}\begin{array}{l}\text { grote massa paraffine-achtig } \\
\text { materiaal }\end{array} \\
\end{array}$ & 16 & Duidelijke alkaanreeks wijst op paraffine \\
\hline NET-2015-023 & Uieland NSO 4052 & 25-Dec-2015 & 1 & M & $A D$ & 6.2 & maag & paraffine-achtig materiaal & 56 & palmvetten \\
\hline NET-2016-019 & $\begin{array}{l}\text { Ouddorp Zeeland of } 3 \\
\text { birds } \mathrm{nr} 3\end{array}$ & 29-Apr-2016 & 1 & $\mathrm{~F}$ & $2 Y$ & 4.0 & maag & wit wasachtig materiaal & 17 & Duidelijke alkaanreeks wijst op paraffine \\
\hline NET-2016-020 & Vieland Viehors & 21-May-2016 & 2 & $\mathrm{~F}$ & IM & 18.0 & maag & paraffine-achtig materiaal & 60 & o.a. palmvetten \\
\hline NET-2017-027 & Voorne Ouddorp & 17-Sep-2017 & 2 & $\mathrm{~F}$ & $A D$ & 6.0 & maag & meerdere brokjes & 18 & palmvetten \\
\hline NET-2017-035 & $\begin{array}{l}\text { Texel Noordzeestrand } \\
\text { paal 23-24 }\end{array}$ & 17-Dec-2017 & 6 & $\mathrm{~F}$ & $2 Y$ & 1.0 & maag & was-achtig materiaal & 19 & $\begin{array}{l}\text { palmvetten, maar ook piek van 2, 6, 10-Trimethyl } \\
\text { hexadecaan }\end{array}$ \\
\hline NET-2018-001 & $\begin{array}{l}\text { Texel De Dennen } \\
\text { Tureluurspad; inland }\end{array}$ & 5-Jan-2018 & 2 & M & AD & 2.0 & maag & $\begin{array}{l}\text { paraffine-achtig materiaal en } \\
\text { veren }\end{array}$ & 20 & palmvetten (ook sporen paraffine) \\
\hline & & & & & & & Totalen & \multicolumn{2}{|c|}{ paraffine (of fossiel olie gerelateerd) } & 10 \\
\hline & & & & & & & & \multicolumn{2}{|c|}{ plantaardige vetten (palmvet) } & 13 \\
\hline & & & & & & & & \multicolumn{2}{|c|}{ onduidelijk } & 9 \\
\hline
\end{tabular}


In niet alle gevallen was identificatie mogelijk. In zeker $31 \%$ van de gevallen (10 uit 32 ) was sprake van duidelijke alkaanreeksen in de begin analyses. Deze interpreteren we als bewijs voor paraffine of daarmee verwante aardolie producten. Verdere analyses toonden geen, of een te zwakke respons voor de aanwezigheid van alkanen. In $40 \%$ van de analyses (13 uit 32) bleek sprake van plantaardige vetten, veelal vormen van palmvet. In 9 gevallen was sprake van substanties van onduidelijke herkomst. Driemaal werden duidelijke pieken van 2,6,10-Trimethyl hexadecaan gezien waarvan de betekenis nog onduidelijk is. Er zijn geen aanwijzingen dat de aangetroffen stoffen specifiek bij een sexe of leeftijdsgroep worden aangetroffen. In de meeste gevallen zijn de dieren waarin verdachte substanties werden aangetroffen volledig vermagerd, een proces dat dan hoogstwaarschijnlijk is begonnen voordat de verdachte substantie in de maag kwam. Vier vogels hadden nog een middelmatige tot goede conditie (conditie index 4 tot 9) waarbij eventueel wel een link vermoed kan worden tussen het eten van schadelijke substanties en de dood van het individu. In drie van deze gevallen betrof de maaginhoud plantaardige vetten, in een geval paraffine. 


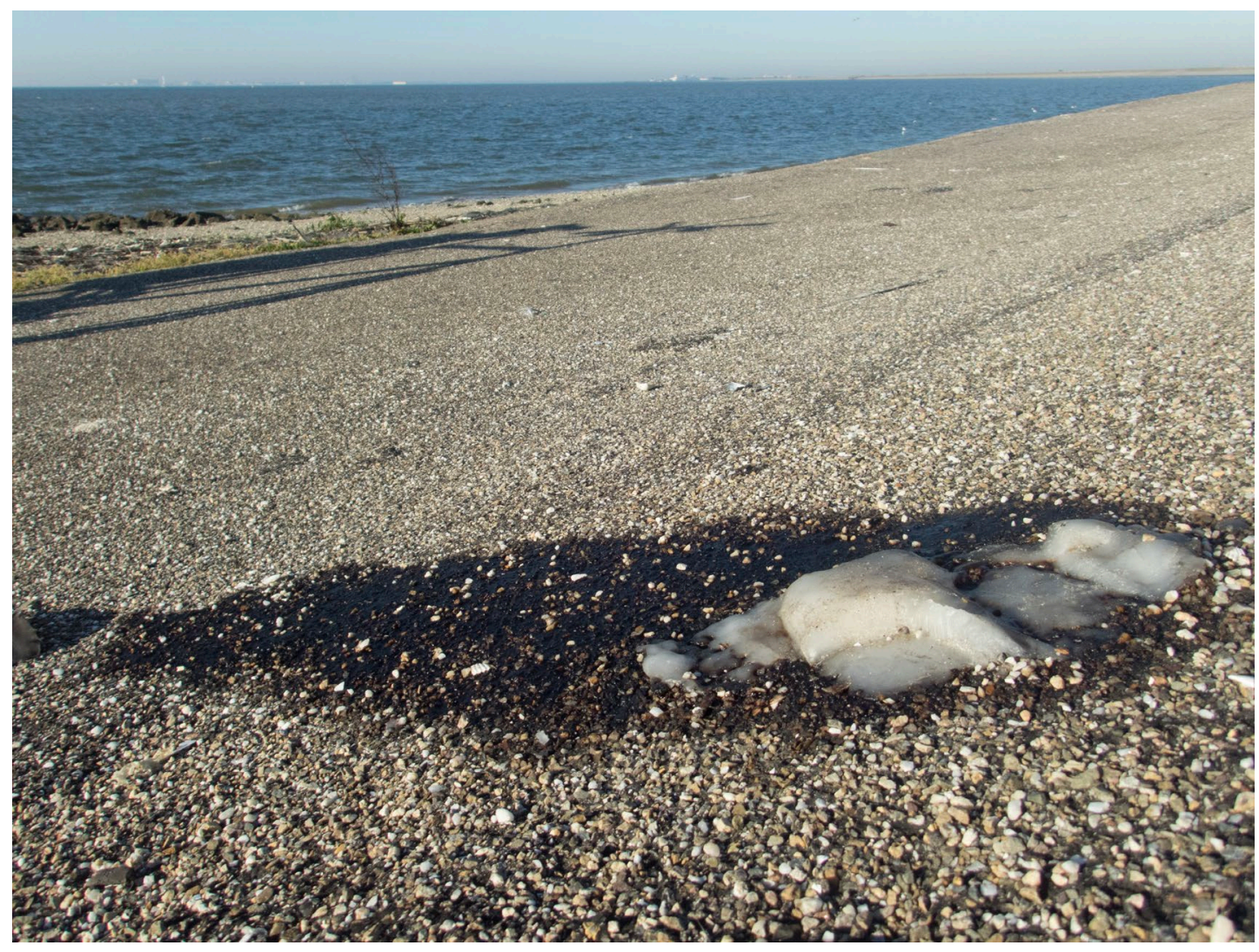

Figuur 10 Bij zonnig warm weer, zeker op donkere ondergrond, smelten paraffine- of palmvetachtige substanties snel weg. Op het strand tussen het zand zijn zulke processen eigenlijk niet waarneembaar.

Figure 10 During sunny warm weather, and certainly on a dark surface, paraffin- or palmfat like substances easily melt and disappear. On the beach in between the sand, such processes cannot be traced. 
In deze verkennende studie zijn monsters van paraffine- of palmvet achtige materialen afkomstig van zowel Nederlandse stranden als uit magen van hier aangespoelde Noordse Stormvogels nader bekeken. De geselecteerde monsters waren afkomstig uit een langere periode. De onderzochte stoffen hebben naar beste weten maar één mogelijke bron, namelijk het schoonmaken van de ruimen van bulktankers die vloeibare vormen van paraffinen en vetten zoals palmolie transporteren. Onder voorwaarden mag het schonen van de ruimen worden uitgevoerd op zee. In 2004 is besloten tot een aanscherping van de regels die in 2007 van kracht zijn geworden.

De nu ontwikkelde methode van analyse is gericht op het kunnen maken van onderscheid tussen lozingen en effecten van paraffine ten opzichte van die van vooral plantaardige vetten als palmolie. Met redelijke zekerheid is aangetoond dat een duidelijk patroon van alkanen wijst op paraffinen, hoewel mogelijk ook andere nauw aan ruwe aardolie verwante stoffen vergelijkbare patronen opleveren. Dit zou nader moeten worden uitgetest.

Bij nadere analyses van de vetten in de monsters zonder alkaanpieken is het een probleem dat veel vetten zowel een plantaardige als dierlijke oorsprong kunnen hebben. Dierlijke vetten komen uiteraard ook het in het gewone dieet voor. Maar niet duidelijk traceerbare vetten kunnen dus zeker van scheepstransporten van vetten afkomstig zijn. En zou veel uitgebreider en dus kostbaarder chemisch onderzoek noodzakelijk zijn om de bestanddelen en eventuele toevoegingen te kunnen identificeren.

Er bleek tussen de twee types monsters, strand en vogelmagen, een opmerkelijk verschil te bestaan in de frequentie van voorkomen van paraffine-achtige stoffen in vergelijking met veelal plantaardige vetten zoals palmolie.

Onder de op het strand gevonden 32 monsters bestond $94 \%$ uit materialen met duidelijke alkaanpieken, wijzend op paraffine of vergelijkbare stoffen. Slechts één van de aangetroffen monsters bevatte palmvetten, en één monster bleef onduidelijk, maar bevatte wel ftalaten (weekmakers uit plastic industrie). Voorafgaand aan dit onderzoek hadden de auteurs het idee dat wittige brokken materiaal in het algemeen paraffine zouden zijn, terwijl geelbruine, en vaak zachtere brokken geacht werden strandingen van palmvet-achtige stoffen te zijn. Beide types waren algemeen in de van het strand verzamelde monsters: dit onderzoek toont dus aan dat deze visuele kenmerken geen betrouwbaar criterium zijn.

Van de 32 samples van verdachte substanties uit de vogelmagen bevatte niet meer dan $31 \%$ paraffine-achtig materiaal, terwijl $41 \%$ plantaardige vetten bevatte, veelal palmolie-achtige stoffen. In de overige samples waren aanwezig vetten niet goed toe te wijzen aan plantaardige of dierlijke bronnen, maar het is goed mogelijk dat een substantieel deel van de gevonden materialen ook afkomstig is van scheepstransporten, en niet uit natuurlijk voedsel.

Dat stormvogels verhoudingsgewijs beduidend vaker palmvetten in de maag hebben dan we op stranden terug zien, heeft verschillend mogelijke verklaringen. Het is goed mogelijk dat geur of andere kenmerken de plantaardige of dierlijke vetten aantrekkelijker maken om te eten dan paraffine. Daarnaast kan snellere biologische afbraak van vetten door micro-organismen of opeten door grotere diersoorten veel vetten sneller en deels op zee doen verdwijnen. Tenslotte is ook mogelijk is dat een hoger smeltpunt van paraffine de stof resistenter maakt tegen fysische afbraak en dus vaker op stranden belandt, en daar langer in vaste herkenbare vorm aanwezig blijft (Figuur 10).

Of het eten van paraffine of palmvetten schadelijk is voor de dieren die het materiaal eten, is niet duidelijk. Bijna alle vogels in dit onderzoek waren sterk vermagerd, hetgeen een direct toxisch dodelijk effect niet waarschijnlijk maakt, maar een indirecte bijdrage ook niet uitsluit. Opmerkelijk is dat van de vier vogels die nog in matige tot goede lichaamsconditie verkeerden, bij drie vogels de 
maaginhoud uit palmvet bestond. Van paraffine zouden eerder negatieve effecten worden verwacht. Bij vogels in goede conditie is niet uit te sluiten dat de maaginhoud in directe relatie staat met de dood van het dier. Over herkomst en eventuele toxische effecten van andere aangetroffen stoffen, met name 2,6,10-Trimethyl hexadecaan is op dit moment geen duidelijkheid. DEHP ftalaat zoals in een op het strand gevonden klomp materiaal met sporen van vogelvraat, wordt veel gebruikt in de plastic industrie en heeft mogelijk o.a. hormoon verstorende werking.

Door jaren heen bevatte ruim $20 \%$ van de magen van op Nederlandse stranden aangespoelde Noordse Stormvogels herkenbare brokjes paraffine- of palmvet-achtig materiaal. In ruim de helft van de gevallen gaat het om meer dan een klein brokje, soms over extreme hoeveelheden (Tabel 2). Gemiddeld over alle ruim 1100 onderzochte stormvogels hebben de in Nederland gevonden stormvogels $0.8 \mathrm{~g}$ verdachte stoffen in de maag.

De enorme variatie in hoeveelheden chemisch verdacht materiaal in de vogelmagen (van 0 tot $110 \mathrm{~g}$ ), maakt een analyse op eventuele trends door de tijd op basis van materiaalgewicht vrijwel onmogelijk. Gebruikelijke methodes op basis van bijv. logaritmische transformatie geven onvoldoende mogelijkheden. Op basis van jaarlijkse frequentie is het waarschijnlijker dat trends te ontdekken zijn, maar deze zijn in ieder geval tot dusverre niet significant. De internationale regels voor het schoonmaken van scheepsruimen met dit soort stoffen zijn per 2007 aangescherpt (MEPC 2004). Over de periode 2008-2017 is de berekende correlatie tussen jaar en frequentie van deze stoffen in magen van stormvogels weliswaar negatief, maar niet significant $(p=0.08)$. Beleidswijzigingen hebben dus niet, althans nog niet op statistisch verantwoord niveau, tot resultaten geleid.

Recent heeft ook Stichting de Noordzee een set paraffine monsters van het Nederlandse strand uit de periode 2016 en 2017 laten analyseren door het laboratorium van Rijkswaterstaat (Boonstra et al. 2018). In 95\% van de 63 monsters werd paraffine aangetroffen waaronder 6 monsters met ook ook andere stoffen. Drie monsters bevatten geen paraffine twee maal betrof dit plantaardige vetten en één maal verweerde stookolie. Onze resultaten over de langere periode van het strand geven een sterk vergelijkbaar resultaat.

Er bestaat helaas geen geschikt materiaal om trends in de tijd van paraffine strandingen anders te analyseren dan met de inhoud van de stormvogelmagen. In de OSPAR Beach Litter Survey wordt de manier van registreren van gegevens niet geschikt geacht voor het evalueren van trends door de tijd (Boonstra \& Hougee 2018).

Paraffine- en palmvet-achtige stoffen in de magen van in Nederland aangespoelde Noordse Stormvogels lijken daarom des te meer een zinvolle uitbreiding van de monitoring van plastics in de magen. Plastics en paraffine-achtige stoffen zijn daarin vergelijkbare en statistisch bruikbare methodes om veranderingen door de tijd te kunnen volgen.

De wijze waarop in dit rapport de chemische kenmerken van aangespoeld stoffen zijn bepaald, moeten beschouwd worden als een verkenning. Verschillende aspecten verdienen nog nadere uitwerking zoals de alkaan respons van aardolie verbindingen anders dan paraffine, en mogelijk betere identificatie van verschillende plantaardige vetten en toegevoegde stoffen. Verdere ontwikkeling van de chemische analyse methoden voor monsters van strand en uit vogelmagen, maar bv ook voor veermonsters, lijkt goede perspectieven te bieden. 
BBC News 2013. Dog dies after eating white substance on Cornwall beach. http://www.bbc.co.uk/news/uk-england-cornwall-24608337

Boonstra, M. \& Hougee, M. 2018. OSPAR Beach Litter Monitoring In the Netherlands 2012-2017. Annual Report. The North Sea foundation. Rijkswaterstaat Rapport nr BM 17.16 SDN Utrecht.35pp. http://publicaties.minienm.nl/documenten/ospar-beach-litter-monitoring-in-thenetherlands-2012-2017-annual-report

Boonstra, M., Francken, M. \& Hougee, M. 2018. Analyse van paraffine monsters verzameld op de Nederlandse kust, 2017. Rapportage. Stichting De Noordzee Utrecht. 49 pp + bijlage http://publicaties.minienm.nl/download-bijlage/98160/paraffine-rapport-12102018-def.pdf http://publicaties.minienm.nl/download-bijlage/98159/bijlage-iii-fid-beachcleanup-2016-en2017.pdf.

Camphuysen C.J. 2018. Monitoring and assessment of the proportion of oiled Common Guillemots in The Netherlands: annual update winter 2016/17, with a preview into 2017/18 . NIOZ Report 2018-04, RWS Centrale Informatievoorziening BM 18.06, May 2017. Royal Netherlands Institute for Sea Research, Texel. http://publicaties.minienm.nl/download-bijlage/90861/monitoring-andassessment-of-the-proportion-of-oiled-common-guillemots-in-the-netherlands-annual-updatewinter-2016-17-with-a-preview-into-2017-18.pdf .

Dahlmann, G., Timm, D., Averbeck, C. Camphuysen, C., Skov, H., Durinck, J. 1994. Oiled seabirds Comparative investigations on oiled seabirds and oiled beaches in the Netherlands, Denmark and Germany (1990-93). Marine Pollution Bulletin 28: 305-310. https://www.researchgate.net/publication/287490236

Grand View Research 2017. Paraffin Wax Market Analysis By Application (Candles, Packaging, Cosmetics, Hotmelts, Board Sizing, Rubber), By Region (North America, Europe, Asia Pacific, Central \& South America, Middle East \& Africa), By Country, And Segment Forecasts, 2014 2025. Report ID: 978-1-68038-520-5. San Francisco, LA, p. 88. http://www.reportlinker.com/p04785464-summary/view-report.htm/

MEPC 2004. Revised Annex II of MARPOL 73/78 (Amendments to the annex of the protocol of 1978 relating to the international Convention for the Prevention of Pollution from Ships, 1973). Resolution MEPC 118 (52) Marine Environment Protection Committee IMO, London, 67 pp. http://www.imo.org/en/KnowledgeCentre/IndexofIMOResolutions/Marine-EnvironmentProtection-Committee-(MEPC)/Documents/MEPC.118(52).pdf

Roose, P., Albaiges, J., Bebianno, M.J., Camphuysen, C., Cronin, M., de Leeuw, J., Gabrielsen, G., Hutchinson, T., Hylland, K., Jansson, B., Jenssen, B.M., Schulz-Bull, D., Szefer, P., Webster, L., Bakke, T., Janssen, C. (2011). Chemical Pollution in Europe's Seas: Programmes, Practices and Priorities for Research, Marine Board Position Paper 16. Calewaert, J.B. and McDonough N. (Eds.). Marine Board-ESF, Ostend, Belgium.

http://www.marineboard.eu/sites/marineboard.eu/files/public/publication/Monitoring\%20Chemic al\%20Pollution-71.pdf

Sergeant, E.S.G. 2019. Epitools epidemiological calculators. Ausvet Pty Ltd. at: http://epitools.ausvet.com.au.

Van Franeker, J.A. 1985. Plastic Ingestion in the North Atlantic Fulmar. Marine Pollution Bulletin 16: 367-369 https://doi.org/10.1016/0025-326X(85)90090-6

Van Franeker, J.A. 2004. Save the North Sea Fulmar Litter EcoQO Manual Part 1: Collection and Dissection Procedures. Alterra, Wageningen. http://edepot.wur.nl/40451

Van Franeker, J.A. \& Meijboom, A. 2002. Litter NSV - Marine litter monitoring by Northern Fulmars: a pilot study. ALTERRA-Rapport 401. (Alterra, Wageningen, 72pp). http://edepot.wur.nl/45695

Van Franeker, J.A., Blaize, C., Danielsen, J., Fairclough, K., Gollan, J., Guse, N., Hansen, P.L., Heubeck, M., Jensen, J.-K., Le Guillou, G., Olsen, B., Olsen, K.O., Pedersen, J., Stienen, E.W.M. \& Turner, D.M. 2011. Monitoring plastic ingestion by the northern fulmar Fulmarus glacialis in the North Sea. Environmental Pollution 159: 2609-2615. http://dx.doi.org/10.1016/j.envpol.2011.06.008

Van Franeker, J.A. \& Law, K.L. 2015. Seabirds, Gyres and Global Trends in Plastic Pollution. Environmental Pollution 203: 89-96 http://dx.doi.org/10.1016/j.envpol.2015.02.034 .

Van Franeker J.A. \& Kühn S. 2018. Fulmar Litter EcoQO Monitoring in the Netherlands - Update 2017. Wageningen Marine Research Report C060/18 \& RWS Centrale Informatievoorziening BM 18.20, Den Helder, pp 60. https://doi.org/10.18174/458857

Venables, V.N. \& Ripley, B.D. 2002. Modern applied statistics with S, fourth ed. Springer, New York, 503pp.http://www.bagualu.net/wordpress/wpcontent/uploads/2015/10/Modern_Applied_Statistics_Wi th_S.pdf 


\section{Bijlage / Appendix}

Bijlage Tabel 1. met gedetailleerde gegevens per jaar over het voorkomen van paraffine-achtige stoffen in de magen van dood aangespoelde Noordse Stormvogels in Nederland.

Appendix Table 1 showing the detailed annual data on abundance of paraffin- or palmfat-like substances in the stomachs of beached Northern Fulmars in the Netherlands

\begin{tabular}{|c|c|c|c|c|c|c|c|}
\hline \multicolumn{8}{|c|}{ Potential chemical substances like paraffin } \\
\hline Year & $\begin{array}{c}\text { sample } \\
n\end{array}$ & $(\% a d)$ & $\% F O$ & $\begin{array}{c}\text { average number } \\
n \pm \mathrm{se}\end{array}$ & $\begin{array}{c}\text { average mass } \\
\mathrm{g} \pm \mathrm{se}\end{array}$ & $\begin{array}{l}\text { maximum } \\
\text { mass }\end{array}$ & $\begin{array}{c}\text { Geometri } \\
\text { c mean } \\
\text { mass }\end{array}$ \\
\hline 1979 & 1 & $(0 \%)$ & $0 \%$ & & & & \\
\hline 1980 & 0 & & & & & & \\
\hline 1981 & 0 & & & & & & \\
\hline 1982 & 3 & $(0 \%)$ & $0 \%$ & & & & \\
\hline 1983 & 19 & $(41 \%)$ & $0 \%$ & $0.0 \pm 0.0$ & $0.00 \pm 0.00$ & 0.0 & 0.0000 \\
\hline 1984 & 20 & $(40 \%)$ & $25 \%$ & $0.3 \pm 0.1$ & $0.56 \pm 0.35$ & 5.3 & 0.0037 \\
\hline 1985 & 3 & $(33 \%)$ & $0 \%$ & & & & \\
\hline 1986 & 4 & $(25 \%)$ & $0 \%$ & & & & \\
\hline 1987 & 17 & $(59 \%)$ & $12 \%$ & $0.2 \pm 0.1$ & $0.06 \pm 0.06$ & 1.0 & 0.0010 \\
\hline 1988 & 1 & $(0 \%)$ & $0 \%$ & & & & \\
\hline 1989 & 2 & $(100 \%)$ & $0 \%$ & & & & \\
\hline 1990 & 0 & & & & & & \\
\hline 1991 & 1 & $(0 \%)$ & $0 \%$ & & & & \\
\hline 1992 & 0 & & & & & & \\
\hline 1993 & 0 & & & & & & \\
\hline 1994 & 0 & & & & & & \\
\hline 1995 & 2 & $(50 \%)$ & $0 \%$ & & & & \\
\hline 1996 & 8 & $(62 \%)$ & $50 \%$ & & & & \\
\hline 1997 & 31 & $(16 \%)$ & $6 \%$ & $0.2 \pm 0.1$ & $0.00 \pm 0.00$ & 0.0 & 0.0002 \\
\hline 1998 & 74 & $(45 \%)$ & $30 \%$ & $1.3 \pm 0.4$ & $1.23 \pm 0.73$ & 50.0 & 0.0042 \\
\hline 1999 & 107 & $(70 \%)$ & $33 \%$ & $3.3 \pm 0.9$ & $0.28 \pm 0.11$ & 9.0 & 0.0030 \\
\hline 2000 & 38 & $(58 \%)$ & $26 \%$ & $2.4 \pm 0.9$ & $0.06 \pm 0.04$ & 1.6 & 0.0016 \\
\hline 2001 & 55 & $(37 \%)$ & $15 \%$ & $0.6 \pm 0.3$ & $1.70 \pm 1.26$ & 67.0 & 0.0013 \\
\hline 2002 & 56 & $(54 \%)$ & $23 \%$ & $2.9 \pm 1.3$ & $0.03 \pm 0.02$ & 0.8 & 0.0013 \\
\hline 2003 & 39 & $(56 \%)$ & $21 \%$ & $0.9 \pm 0.5$ & $1.94 \pm 1.67$ & 65.0 & 0.0026 \\
\hline 2004 & 131 & $(80 \%)$ & $18 \%$ & $1.7 \pm 0.5$ & $0.25 \pm 0.20$ & 26.0 & 0.0011 \\
\hline 2005 & 51 & $(68 \%)$ & $31 \%$ & $2.2 \pm 1.1$ & $0.69 \pm 0.59$ & 30.0 & 0.0024 \\
\hline 2006 & 27 & $(62 \%)$ & $37 \%$ & $2.1 \pm 1.0$ & $0.03 \pm 0.01$ & 0.3 & 0.0028 \\
\hline 2007 & 62 & $(43 \%)$ & $18 \%$ & $0.7 \pm 0.3$ & $1.32 \pm 0.90$ & 51.0 & 0.0023 \\
\hline 2008 & 20 & $(58 \%)$ & $30 \%$ & $1.2 \pm 0.5$ & $0.14 \pm 0.08$ & 1.4 & 0.0031 \\
\hline 2009 & 68 & $(40 \%)$ & $12 \%$ & $0.2 \pm 0.1$ & $0.98 \pm 0.75$ & 50.0 & 0.0013 \\
\hline 2010 & 36 & $(46 \%)$ & $44 \%$ & $3.4 \pm 1.5$ & $0.64 \pm 0.31$ & 10.0 & 0.0088 \\
\hline 2011 & 19 & $(37 \%)$ & $21 \%$ & $3.2 \pm 2.7$ & $0.02 \pm 0.01$ & 0.3 & 0.0011 \\
\hline 2012 & 81 & $(46 \%)$ & $17 \%$ & $0.5 \pm 0.2$ & $1.31 \pm 0.61$ & 41.5 & 0.0024 \\
\hline 2013 & 24 & $(42 \%)$ & $17 \%$ & $0.2 \pm 0.1$ & $6.04 \pm 4.75$ & 110.0 & 0.0021 \\
\hline 2014 & 12 & $(64 \%)$ & $25 \%$ & $1.0 \pm 0.5$ & $0.03 \pm 0.02$ & 0.2 & 0.0022 \\
\hline 2015 & 22 & $(32 \%)$ & $27 \%$ & $1.0 \pm 0.6$ & $2.16 \pm 1.82$ & 40.0 & 0.0041 \\
\hline 2016 & 31 & $(18 \%)$ & $6 \%$ & $0.7 \pm 0.6$ & $0.71 \pm 0.59$ & 18.0 & 0.0008 \\
\hline 2017 & 36 & $(32 \%)$ & $11 \%$ & $0.9 \pm 0.6$ & $0.20 \pm 0.17$ & 6.0 & 0.0010 \\
\hline
\end{tabular}


Bijlage Tabel 2. Tabel met gedetailleerde gegevens per lopende 5-jaar periodes over het voorkomen van paraffine-achtige stoffen in de magen van dood aangespoelde Noordse Stormvogels in Nederland. Gegevens voor de jaren '80 zijn in één getal gecombineerd.

Appendix Table 2 showing the detailed data on abundance of paraffin-or palmfat-like substances the stomachs of beached Northern Fulmars in the Netherlands in five year running averages.

Data prior 1990 all combined.

\section{Potential chemical substances like paraffin}

\begin{tabular}{|c|c|c|c|c|c|c|c|}
\hline $\begin{array}{l}5 \text {-year } \\
\text { period }\end{array}$ & $\begin{array}{c}\text { sample } \\
n\end{array}$ & $(\% a d)$ & $\% F O$ & $\begin{array}{c}\text { average number } \\
\mathrm{n} \pm \mathrm{se}\end{array}$ & $\begin{array}{c}\text { average mass } \\
\mathrm{g} \pm \mathrm{se}\end{array}$ & $\begin{array}{l}\text { maximum } \\
\text { mass }\end{array}$ & $\begin{array}{c}\text { Geometri } \\
\mathrm{c} \text { mean } \\
\text { mass } \\
\end{array}$ \\
\hline 1979-89 & 70 & $(43 \%)$ & $10 \%$ & $0.1 \pm 0.0$ & $0.18 \pm 0.10$ & 5.3 & 0.0008 \\
\hline 1990-94 & 1 & & & & & & \\
\hline 1991-95 & 3 & & & & & & \\
\hline 1992-96 & 10 & & & & & & \\
\hline 1993-97 & 41 & $(27 \%)$ & $15 \%$ & $0.5 \pm 0.2$ & $0.39 \pm 0.29$ & 10.7 & 0.0011 \\
\hline 1994_98 & 115 & $(38 \%)$ & $24 \%$ & $1.0 \pm 0.3$ & $0.93 \pm 0.48$ & 50.0 & 0.0027 \\
\hline 1995_99 & 222 & $(53 \%)$ & $28 \%$ & $2.1 \pm 0.4$ & $0.62 \pm 0.25$ & 50.0 & 0.0029 \\
\hline 1996_00 & 258 & $(54 \%)$ & $28 \%$ & $2.1 \pm 0.4$ & $0.54 \pm 0.22$ & 50.0 & 0.0027 \\
\hline 1997_01 & 305 & $(51 \%)$ & $25 \%$ & $1.9 \pm 0.4$ & $0.71 \pm 0.29$ & 67.0 & 0.0022 \\
\hline 1998_02 & 330 & $(55 \%)$ & $27 \%$ & $2.2 \pm 0.4$ & $0.66 \pm 0.27$ & 67.0 & 0.0024 \\
\hline 1999_03 & 295 & $(57 \%)$ & $25 \%$ & $2.3 \pm 0.4$ & $0.69 \pm 0.33$ & 67.0 & 0.0020 \\
\hline 2000_04 & 319 & $(62 \%)$ & $19 \%$ & $1.7 \pm 0.3$ & $0.65 \pm 0.31$ & 67.0 & 0.0014 \\
\hline 2001_05 & 332 & $(64 \%)$ & $20 \%$ & $1.7 \pm 0.4$ & $0.72 \pm 0.31$ & 67.0 & 0.0015 \\
\hline 2002_06 & 304 & $(68 \%)$ & $23 \%$ & $1.9 \pm 0.4$ & $0.48 \pm 0.25$ & 65.0 & 0.0016 \\
\hline 2003_07 & 310 & $(66 \%)$ & $22 \%$ & $1.5 \pm 0.3$ & $0.73 \pm 0.30$ & 65.0 & 0.0018 \\
\hline 2004_08 & 291 & $(67 \%)$ & $23 \%$ & $1.6 \pm 0.3$ & $0.53 \pm 0.24$ & 51.0 & 0.0017 \\
\hline 2005_09 & 228 & $(51 \%)$ & $22 \%$ & $1.1 \pm 0.3$ & $0.82 \pm 0.36$ & 51.0 & 0.0021 \\
\hline 2006_10 & 213 & $(46 \%)$ & $24 \%$ & $1.2 \pm 0.3$ & $0.82 \pm 0.36$ & 51.0 & 0.0027 \\
\hline 2007_11 & 205 & $(43 \%)$ & $22 \%$ & $1.3 \pm 0.4$ & $\mathbf{0 . 8 5} \pm \mathbf{0 . 3 7}$ & 51.0 & 0.0025 \\
\hline 2008_12 & 224 & $(44 \%)$ & $21 \%$ & $1.2 \pm 0.3$ & $0.89 \pm 0.32$ & $\mathbf{5 0 . 0}$ & 0.0025 \\
\hline 2009_13 & 228 & $(43 \%)$ & $20 \%$ & $1.1 \pm 0.3$ & $1.50 \pm 0.59$ & 110.0 & 0.0024 \\
\hline 2010_14 & 172 & $(45 \%)$ & $24 \%$ & $1.4 \pm 0.4$ & $1.60 \pm 0.73$ & 110.0 & 0.0030 \\
\hline 2011_15 & 158 & $(43 \%)$ & $20 \%$ & $0.9 \pm 0.3$ & $1.90 \pm 0.83$ & 110.0 & 0.0024 \\
\hline 2012_16 & 170 & $(40 \%)$ & $17 \%$ & $0.6 \pm 0.2$ & $1.89 \pm 0.77$ & 110.0 & 0.0022 \\
\hline 2013_17 & 125 & $(34 \%)$ & $15 \%$ & $0.7 \pm 0.3$ & $1.78 \pm 0.98$ & 110.0 & 0.0016 \\
\hline
\end{tabular}


Bijlage Tabel 3 Details van lineaire regressie zoals gebruikt in plastic monitoring. Hier minder geschikt, onder andere door de vele nulwaardes die een complicatie vormen in de vereiste log transformaties

Appendix Table 3. Details of linear regression as used in the plastic monitoring program. Such analysis is less suitable, amongst other for reason of the many zero values, which complicate the data transformation required for the analysis

Linear regression for trends over time as used in plastic analyses (less suitable because In transformation required, and chemicals have lots of zeros)

Trend analysis on mass of suspected chemical substances in fulmar stomachs

\begin{tabular}{lcrrrrrr} 
& $\boldsymbol{n}$ & constant & slope & s.e. & t & p & \\
\cline { 1 - 5 } 10 year trend 2008-2017 & 349 & 108.0 & -0.0564 & 0.0507 & -1.11 & 0.267 & n.s. \\
Trend since start SNS study 2002-2017 & 715 & -25.2 & 0.0097 & 0.0203 & 0.47 & 0.635 & n.s. \\
Long-term trend 1979-2017 & 1101 & -21.7 & 0.0079 & 0.0098 & 0.81 & 0.416 & n.s. \\
\cline { 1 - 7 }
\end{tabular}




\section{$9 \quad$ Kwaliteitsborging}

Wageningen Marine Research beschikt over een ISO 9001:2015 gecertificeerd kwaliteitsmanagementsysteem. Dit certificaat is geldig tot 15 december 2021. De organisatie is gecertificeerd sinds 27 februari 2001. De certificering is uitgevoerd door DNV GL.

Het chemisch laboratorium te IJmuiden beschikt over een NEN-EN-ISO/IEC 17025:2005 accreditatie voor testlaboratoria met nummer L097. Deze accreditatie is geldig tot 1 april 2021 en is voor het eerst verleend op 27 maart 1997; deze accreditatie is verleend door de Raad voor Accreditatie. Het chemisch laboratorium heeft hierdoor aangetoond in staat te zijn op technisch bekwame wijze valide resultaten te leveren en te werken volgens de IS017025 norm. De scope (L097) met de geaccrediteerde analysemethoden is te vinden op de website van de Raad voor Accreditatie (www.rva.nl).

Op grond van deze accreditatie is het kwaliteitskenmerk $\mathrm{Q}$ toegekend aan de resultaten van die componenten die op de scope staan vermeld, mits aan alle kwaliteitseisen is voldaan.

De analyse van paraffine achtige componenten is niet geaccrediteerd, het kwaliteitskenmerk $\mathrm{Q}$ wordt niet vermeld in de tabellen met de onderzoeksresultaten.

De kwaliteit van de analysemethoden wordt op verschillende manieren gewaarborgd. De juistheid van de analysemethoden wordt regelmatig getoetst door deelname aan ringonderzoeken waaronder die georganiseerd door QUASIMEME. Indien geen ringonderzoek voorhanden is, wordt een tweede lijnscontrole uitgevoerd. Tevens wordt bij iedere meetserie een eerstelijnscontrole uitgevoerd. Naast de lijnscontroles wordende volgende algemene kwaliteitscontroles uitgevoerd:

- Blanco onderzoek.

- Terugvinding (recovery).

- Interne standaard voor borging opwerkmethode.

- Injectie standard.

- Gevoeligheid.

Bovenstaande controles staan beschreven in Wageningen Marine Research werkvoorschrift ISW 2.10.2.105.

Indien gewenst kunnen gegevens met betrekking tot de prestatiekenmerken van de analysemethoden bij het chemisch laboratorium worden opgevraagd.

Indien sprake is van onbeheerste kwaliteit worden passende maatregelen genomen. 


\section{Verantwoording}

Rapport $\quad$ C001/19

Projectnummer: $\quad$ KB-24-002-036 (WMR projectnummer 4318300057

Dit rapport is met grote zorgvuldigheid tot stand gekomen. De wetenschappelijke kwaliteit is intern getoetst door een collega-onderzoeker en het verantwoordelijk lid van het managementteam van Wageningen Marine Research

Akkoord:

Martin Baptist

Senior onderzoeker

Handtekening:

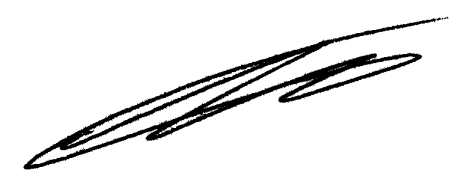

Datum:

11 maart 2019

Akkoord:
Handtekening:
Datum: 
Wageningen Marine Research

$\mathrm{T}:+31(0) 317480900$

E: marine-research@wur.nl

www.wur.nl/marine-research

Bezoekers adres:

- Ankerpark 271781 AG Den Helder

- Korringaweg 7, 4401 NT Yerseke

- Haringkade 1, 1976 CP IJmuiden
Wageningen Marine Research levert met kennis, onafhankelijk wetenschappelijk onderzoek en advies een wezenlijke bijdrage aan een duurzamer, zorgvuldiger beheer, gebruik en bescherming van de natuurlijke rijkdommen in zee-, kust- en zoetwatergebieden. 